\title{
CARBON DIOXIDE AND OXYGEN TENSIONS OF THE MIXED VENOUS BLOOD OF MAN AT REST
}

\author{
BY DICKINSON W. RICHARDS, JR. AND MARJORIE L. STRAUSS \\ (From the Department of Medicine, Columbia University, College of Physicians and Surgeons, \\ and the Presbyterian Hospital, New York)
}

(Received for publication June 30, 1930)

PART I

THE PROBLEM OF EQUILIBRATION OF LUNG GASES WITH INCOMING
VENOUS BLOOD

The state of the mixed venous blood, or the blood in the right side of the heart and in the pulmonary artery, especially in respect to its oxygen and carbon dioxide contents, has been of interest since Fick's principle (1) of measuring circulation rate was enunciated in 1870.

In animals' the study of this blood can be made directly by puncture of the right side of the heart or by insertion of canulae through the jugular vein into the right auricle. In man such procedures have not usually been considered justified for purposes of experimental study, and recourse has therefore been had to the use of the lungs as an aerotonometer, in the attempt to bring the lung gases into equilibrium with inflowing venous (pulmonary artery) blood before recirculation alters the character of this inflowing blood. Application of these tensions to oxygen or carbon dioxide dissociation curves of the blood then gives the $\mathrm{O}_{2}$ and $\mathrm{CO}_{2}$ contents of the mixed venous blood. Numerous methods on this principle have been devised.

Very recently some experiments have been performed with human subjects, in which blood from the right heart was obtained directly. These will be referred to later.

Loewy and von Schrötter (2) in 1905 performed some experiments in which they passed a catheter down the subject's trachea and into one of the large bronchi; then closed off the bronchus by inflating a small rubber bag around the catheter. This portion of thelung thus acted as a closed tonometer. When sufficient time had elapsed in order for 
equilibrium to be reached, a sample of the air was withdrawn through the catheter. The sample was supposed to have the same tensions of $\mathrm{O}_{2}$ and $\mathrm{CO}_{2}$ as the incoming venous blood. This method assumed that the procedure did not appreciably affect the general circulorespiratory equilibrium; and it also called for considerable heroism on the part of the subject. It has been little used since.

Four years later Plesch (3) developed the technique of rebreathing gas mixtures in and out of a rubber bag. He attempted to bring the rebreathed mixture into equilibrium both with the $\mathrm{O}_{2}$ and $\mathrm{CO}_{2}$ of the venous blood. In order to make the oxygen of the mixture sufficiently low, a preliminary rebreathing of pure nitrogen was employed. Plesch was the first to make the assumption that if, after successive periods of rebreathing, the gases in the bag reached constant values, these values therefore represented equilibrium with the incoming venous blood. We shall return later to a consideration of this assumption.

The measurement in 1914 by Christiansen, Douglas, and Haldane (4) of the effect of oxygenation upon the $\mathrm{CO}_{2}$ dissociation curves of whole blood led to a further simplification of technique. If a proper mixture of $\mathrm{CO}_{2}$ and air (or $\mathrm{CO}_{2}$ and $\mathrm{O}_{2}$ ) were rebreathed, it should be possible to oxygenate the incoming blood, without at the same time causing any alteration in its $\mathrm{CO}_{2}$ content. The $\mathrm{CO}_{2}$ tension of this blood will, of course, be raised over the true venous level, due to its oxygenation. Blood in this state was called "oxygenated venous," or (Y. Henderson and Prince (8)) "virtual venous" blood. The technique of Christiansen, Douglas, and Haldane was as follows: the subject, after a short preliminary rest period, inhaled from a small rubber bag a mixture of from 6.5 to 10.0 per cent $\mathrm{CO}_{2}$ in air (sometimes $\mathrm{CO}_{2}$ in oxygen), held the mixture in the lungs $4 \frac{1}{2}$ seconds, then expired about 1 liter, held the breath 6 seconds longer, then made a complete expiration. Samples of the two fractions were analyzed. In some experiments three partial expirations were made, at 4, 9, and 13 seconds. If the $\mathrm{CO}_{2}$ values of these successive samples were the same, or nearly so, it was believed that equilibrium had been obtained. Further evidence of equilibrium was obtained by having the subject rebreathe successively (a) a mixture which when mixed with alveolar air would give a $\mathrm{CO}_{2}$ tension higher than the oxygenated mixed venous; and then (b) a mixture giving too low a tension. Thus the equilibrium level was ap- 
proached both from above and below. It was assumed here that the lung gases became completely mixed by being simply held in the lungs for $4 \frac{1}{2}$ seconds; and also that the equilibrium with the incoming blood could be reached in $4 \frac{1}{2}$ (or 9) seconds by the necessary transfer of gases to or from the circulating pulmonary blood. Theoretically, if mixture in the lungs were not perfect, it would have been quite possible for an inhaled mixture that was too low to give in the $4 \frac{1}{2}$ second sample a value higher than the completely mixed air, on account of the greater proportion in that sample of air from the bag; while the $10 \frac{1}{2}$ second sample might equal this value by increase of $\mathrm{CO}_{2}$ in it, derived from the blood; without, however, complete equilibrium with the venous blood having been reached at any time. In the cases where successive experiments with different initial mixtures were performed, and good agreement was obtained, this possibility was eliminated.

The results of Christiansen, Douglas, and Haldane showed rather large variations in equilibrium values obtained, between successive experiments, also at times in single experiments agreement of samples was not good. However, the general level of oxygenated mixed venous tension was found, and this marked at the time a signal advance.

The calculations whereby Christiansen, Douglas and Haldane, transferred tensions into terms of blood gas contents were cumbersome, and involved the calculation of the actual mixed venous $\mathrm{CO}_{2}$ tensions.

Fridericia in 1918 (5) determined venous $\mathrm{CO}_{2}$ tensions by a technique similar to that of Christiansen, Douglas, and Haldane, except that when differences were found between the tensions obtained at half and full expiration, he calculated the amounts of $\mathrm{CO}_{2}$ absorbed or given off, and by using varying initial mixtures was able to estimate the tension of zero absorption, or equilibrium. By a method slightly modified from this, Liljestrand and Lindhard in 1920 (6), compared circulation rates as calculated by this and by the Krogh-Lindhard (7) nitrous oxide method, and found satisfactory agreement.

Henderson and Prince (8) in 1917 developed a method for measuring venous tensions similar to that of Plesch with the difference that $\mathrm{CO}_{2}$ alone was measured. The method consisted in making a deep expiration into a bag, then, after a rest interval of several minutes, inhaling this mixture, holding it in the lungs for 5 to 10 seconds, and exhaling it again; this procedure was repeated several times, and it was found that 
a $\mathrm{CO}_{2}$ tension was reached after 3 or 4 trials which remained constant through further rebreathings. This was considered to be the oxygenated venous $\mathrm{CO}_{2}$ tension, and it was suggested that the venous $\mathrm{CO}_{2}$ content could then be obtained by equilibrating a sample of the subject's blood, with this rebreathed air. Henderson and Prince checked their method in two ways: (a) they found that by their method of "intermittent rebreathings" the same final equilibrium tensions were obtained whether they started with a high or low $\mathrm{CO}_{2}$ tension in the rebreathing bag. They also investigated the effects of holding the air in the lungs (or of rebreathing it slowly) for varying lengths of time, from 3 to 20 seconds or more. Thus, they obtained one equilibrium value, with successive periods of rebreathing, each of 3 seconds' duration, another value after a series of rebreathing, each of 10 seconds' duration, and so forth. They found that between 6 and 16 seconds, a "plateau" level was reached, the equilibrium values obtained for these durations of rebreathing, being essentially the same; these values they interpreted to be the oxygenated venous $\mathrm{CO}_{2}$ tension. This was a fairinference, except that they did not know what their oxygen tensions were; and it is possible that the transient interruption in a steady rise of venous $\mathrm{CO}_{2}$. (as represented by the "plateau") was only an apparent equilibrium, due to a falling off of lung $\mathrm{O}_{2}$ tension with consequent check in the $\mathrm{CO}_{2}$ tension rise.

Meakins and Davies (9) in 1922 employed a technique similar to that of Henderson and Prince with the difference that the air was regularly rebreathed in and out of the bag twice, instead of simply being held in the lungs. They believed that in this manner, more perfect mixture could be obtained.

Barcroft, Roughton, and Shoji (10) equilibrated the oxygen in the subject's lungs with that in the venous blood, instead of equilibrating the $\mathrm{CO}_{2}$. This they did by simply rebreathing pure nitrogen. They found in successive trials that the oxygen tension soon reached a constant level each time at the end of 7 or 8 seconds of rebreathing. This level was maintained till about the twentieth second, after which it decreased rapidly. (This latter fact demonstrated the time of onset of recirculation of blood.) The $\mathrm{CO}_{2}$ tension at this equilibrium level was lower than that of true mixed venous blood, on account of the 
large admixture of nitrogen and very low oxygen tension. Barcroft and his associates recognized this and made certain corrections for it.

At about the same time, Redfield, Bock and Meakins (11) devised an extrapolation method for determining simultaneously both the actual $\mathrm{CO}_{2}$ and $\mathrm{O}_{2}$ tensions of mixed venous blood. They rebreathed a given mixture of $\mathrm{CO}_{2}, \mathrm{O}_{2}$ and $\mathrm{N}_{2}$, and took a sample at the end of 5 seconds and another at the end of 10 seconds. These were analyzed, plotted on a $\mathrm{CO}_{2}-\mathrm{O}_{2}$ tension diagram and a line drawn, connecting the two and extrapolated beyond. Similar experiments were done using different initial rebreathed mixtures. It was found that the lines drawn through the various pairs of 5 and 10 second points, when extrapolated, tended to meet at the same point. This was inferred to represent the mixed venous tensions. The procedure assumed that the rate of change of $\mathrm{CO}_{2}$, during equilibration, held a constant ratio to that of $\mathrm{O}_{2}$. The authors found further that the point of intersection of two or more extrapolated lines was also crossed by a horizontal line drawn at the $\mathrm{CO}_{2}$ tension as obtained by the Henderson-Prince technique. This last point casts a certain doubt upon the accuracy of the method; because the Henderson-Prince oxygenated venous $\mathrm{CO}_{2}$ tension ought to have been considerably above their own true mixed venous $\mathrm{CO}_{2}$ tension.

Recently Grollman (12) has compared values of cardiac output as obtained by the use of this extrapolation technique, with similar values by the acetylene method, and finds satisfactory agreement.

In 1922 Douglas and Haldane (13) continued further the experiments which Christiansen, Douglas, and Haldane had made in 1914. Knowing the oxygenated and reduced $\mathrm{CO}_{2}$ dissociation curves and the $\mathrm{O}_{2}$ dissociation curves of their subjects, these workers were able to find both the oxygenated mixed venous $\mathrm{CO}_{2}$ levels and the true mixed venous $\mathrm{CO}_{2}$ and $\mathrm{O}_{2}$ levels in successive experiments on the same day, and compare the arteriovenous differences (or circulation rates), so obtained. The method used differed slightly from their earlier one. A mixture was made up in a Douglas bag which had approximately the desired concentrations of $\mathrm{CO}_{2}$ and $\mathrm{O}_{2}$ (previously determined by a pilot experiment). Three successive complete inspirations were then made from the bag, each inspiration having been preceded by a complete expiration to the outside air. The last inspiration was held 
two seconds, a half expiration made, a sample taken, then after five seconds more a complete expiration made and a second sample taken. If the gas tensions in the two samples were the same, it was concluded that equilibrium had been reached. If not, then the equilibrium tension was obtained by extrapolation, by adding (algebraically) to the second tension the difference between the first and second. This procedure was admittedly empirical but gave consistent results and was therefore accepted.

The results of Douglas and Haldane on several subjects, both at rest and during work, showed essentially the same arteriovenous differences, and therefore the same mixed venous blood contents of $\mathrm{O}_{2}$ and $\mathrm{CO}_{2}$, whether oxygenated or true venous $\mathrm{CO}_{2}$ tensions, or venous oxygen tensions, were used.

In recent months, Ewig and Hinsberg (14) have described a method, similar to that of Douglas and Haldane, except that they purposely employ mixtures which give final values on either side of the equilibrium, and calculate the oxygenated venous tension by interpolation.

The technique used by Eppinger, Papp, and Schwarz (38) was somewhat similar to that of Douglas and Haldane, true venous tensions of $\mathrm{CO}_{2}$ and $\mathrm{O}_{2}$ being obtained.

Murray and Taylor (15) in a brief communication described another method of reaching equilibrium simultaneously with both $\mathrm{CO}_{2}$ and $\mathrm{O}_{2}$. In this method, a mixture of 1.5 per cent $\mathrm{O}_{2}, 6$ per cent $\mathrm{CO}_{2}$ and 92.5 per cent $\mathrm{N}_{2}$ was rebreathed, instantaneous samples taken into evacuated tubes at the end of each expiration, and the resulting $\mathrm{CO}_{2}$ and $\mathrm{O}_{2}$ tension values plotted on a $\mathrm{CO}_{2}-\mathrm{O}_{2}$ tension diagram. At equilibrium, successive samples fell on the same point on the chart. The feature of this method which one may emphasize is that the course of equilibration of each particular experiment was followed by the use of successive instantaneous samples. Christiansen, Douglas, and Haldane had accomplished this also but took fewer samples.

The method of Field, Bock, Gildea, and Lathrop (16) represented a slight modification of that of Meakins and Davies, in that $(a)$ the number of rebreathings was increased to four or five, and $(b)$ the mixture used was 6 per cent $\mathrm{CO}_{2}$ and 94 per cent $\mathrm{O}_{2}$, instead of $\mathrm{CO}_{2}$ and air. The authors showed that with the use of the latter, the $\mathrm{O}_{2}$ tension at the end of several rebreathings was reduced to $65-75 \mathrm{~mm}$.-insuff- 
cient to oxidize the blood completely, and that the $\mathrm{CO}_{2}$ tension was correspondingly 1 to $3 \mathrm{~mm}$. lower than when $\mathrm{CO}_{2}-\mathrm{O}_{2}$ mixtures were rebreathed. They showed also that the same $\mathrm{CO}_{2}$ level was reached at the end of the second as at the end of the sixth rebreathing, thus indicating a plateau level, from which it was inferred that a state of equilibrium had been reached. The matter of the diluting effect of the residual alveolar air was discussed, as to whether this might prevent a true equilibrium with venous blood being attained. This was tested by adding to the bag $12 \mathrm{cc}$. of pure $\mathrm{CO}_{2}$ between rebreathing periods; it was shown in three experiments that the same level was reached in 15-20 seconds, whether the extra $\mathrm{CO}_{2}$ was added or not. In their further experiments, however, in measuring circulation rates in various individuals the mixed venous values were so variable in some instances, and the circulation rates so large, that the question does arise as to whether a true equilibrium with venous blood can be reached by this method in all subjects.

In further work from the same laboratory, recently reported, (17) this possible source of error has been eliminated. The technique now employed is to have the mixture in the rebreathing bag about 2 or 3 $\mathrm{mm}$. higher in $\mathrm{CO}_{2}$ content than the expected oxygenated venous level, thus compensating for the diluting effect of the alveolar air. The present authors also, in a recent communication (18), have reported a similar technique.

Field, Bock, Gildea, and Lathrop confirmed Barcroft, Roughton, and Shoji in demonstrating that at rest, the time when evidences of recirculating blood began to be apparent was at the end of about 20 seconds of rebreathing, the $\mathrm{CO}_{2}$ tension then starting a progressive rise above the plateau level.

The importance of having sufficient oxygen in the rebreathing mixture, in all methods of obtaining oxygenated venous tensions, is stressed in two recent papers by Isräels and Lamb (19).

The most elaborate of all experiments so far reported for arriving at the actual state of the mixed venous blood have been those of Burwell and Robinson (20). These investigators by the use of a double rebreathing system, first washed out the subject's lungs by two respirations from a spirometer containing nitrogen, then completed the equilibration by rebreathing suitable mixtures of $\mathrm{CO}_{2}, \mathrm{O}_{2}$, and $\mathrm{N}_{2}$. 
They took their sample at the end of about 20 seconds from the time of the first respiration. By employing this technique successively with mixtures that were above and below equilibrium levels, in their initial $\mathrm{CO}_{2}$ and $\mathrm{O}_{2}$ tensions, and reaching essentially the same final values with each, they concluded that they had arrived at the true mixed venous tensions. In order to convert tensions into blood gas contents, samples of venous blood were equilibrated in tonometers with the lung air samples obtained at the end of rebreathing.

This method, though laborious, would certainly seem to be as nearly free of theoretical objections as any that has yet been described.

One further point has received special attention recently and that is the question of completeness of mixtuure of the lung gases,- - whether the samples in the rebreathing bag are identical with the air in the pulmonary alveoli. On this subject, Grollman and Marshall (21) have reported some experiments which indicate that only after about 5 rebreathings taking at least 12 to 15 seconds, is such complete mixture obtained. On the other hand, Bock, Dill and Talbott (17) have found that simply holding an inhaled mixture in the lungs for 5 second periods is as efficient in this respect as rebreathing the mixture a greater number of times. Earlier work on this problem was done by Sonne (22).

Hamilton, Moore and Kinsman (23), in a recent paper, have justly criticized the intermittent rebreathing methods, in that in all of these (except where $\mathrm{CO}_{2}$ is added to the bag between rebreathings), irrespective of what the initial rebreathed mixture is, actual equilibrium will will always be arrived at from below, on account of the diluting effect of the residual air in the lungs. They have, however, advanced a further hypothesis, namely, that at any given moment, while the body is at rest, the "blood in the lungs is not wholly venous but more or less arterial in some parts and venous in others, and the tension of the lung air is an expression of the average of these various tensions." On this hypothesis, they believe that it is possible that the continued rebreathing of a $\mathrm{CO}_{2}-\mathrm{O}_{2}$ mixture will only very gradually-in 15 to 20 seconds or more-come into equilibrium with the actual venous (pulmonary artery) blood, being delayed by the arterialized blood in the lungs. We do not see the justification for this latter deduction. Irrespective of how the blood in various individual lung capillaries 
may differ in rate of flow, the blood in these capillaries will be exposed at once to pulmonary gases and will presumably come into equilibrium with these gases promptly; whereas all the blood behind this capillary blood will be mixed venous blood, and all blood in front of the capillary blood will be arterialized blood. If the lung and blood tensions are sufficiently close so that lung-blood equilibrium occurs when blood and gas come in contact in the alveoli, then the only way by which a true general equilibrium can be delayed is by incomplete mixing of gases in various parts of the lungs during the first few seconds of rebreathing. If this were the case, there might be some of the alveolar spaces that remained for these few seconds untouched by the rebreathed $\mathrm{CO}_{2}-\mathrm{O}_{2}$ mixture. Practically this is not a problem with normal individuals, as by proper rebreathing methods, complete mixture of lung gases can readily be obtained.

The experiments reported by Hamilton, Moore and Kinsman are clear. They used a mixture of 6 per cent of $\mathrm{CO}_{2}$ in oxygen in a rebreathing bag. Their subject then rebreathed this mixture for six seconds, rested, rebreathed again for six seconds, and so forth until a constant $\mathrm{CO}_{2}$ tension was found in the bag upon successive rebreathings. The same procedure was employed with 9, 12, 16, and 25 second rebreathing periods. It was found (contrary to Henderson and Prince's work) that no plateau level was reached but that the $\mathrm{CO}_{2}$ tension increased progressively from the sixth to the twenty-fourth second.

This can readily be explained, it seems to us, by the simple hypothesis that in this subject the diluting effect of the residual air is more than can be made up for by passage of $\mathrm{CO}_{2}$ from blood into lungs before recirculation occurs. Another set of experiments is also reported, in which $\mathrm{CO}_{2}$ was added to the bag before each rebreathing. Again no plateau level was found; but here only three rebreathing times were measured, 8, 16, and 24 seconds, so that even if a plateau had existed in the interval from 10 to 20 seconds (where it has usually been reported) the data would not have shown it.

Further evidence of the "partial arterialization" of lung blood, as given by the authors, was that upon rebreathing a $\mathrm{CO}_{2}-\mathrm{O}_{2}$ mixture, the total $\mathrm{CO}_{2}$ in lungs and bag together, appeared to decrease during the first few seconds. This $\mathrm{CO}_{2}$, it was argued was absorbed by the 
arterialized blood in the lungs. It seems more probable, as suggested in a somewhat different connection several years ago by Christiansen, Douglas, and Haldane (4), that the $\mathrm{CO}_{2}$ thus lost passes into the tissue fluids of the lung, in raising them from alveolar to oxygenated venous $\mathrm{CO}_{2}$ tension levels.

Mixed venous values can of course be derived indirectly from cardiac output figures as obtained by foreign-gas inhalation methods, providing the gas contents of the arterial blood, and the minute output of $\mathrm{CO}_{2}$ or absorption of $\mathrm{O}_{2}$, are known. The extensive work that has been done by these methods is outside the scope of the present study.

It is self-evident and well-recognized that all the methods cited above, of obtaining mixed venous blood values, are based on a number of inferences.

The development of a method whereby blood can be drawn from the right heart or pulmonary artery, and compared with "mixed venous" values obtained on the given subject at the same time by one of the indirect methods, will probably be necessary before the absolute accuracy of these methods can be known.

Forssmann (24) recently reported an experiment in which he passed a catheter into his own arm vein, along the subclavian and superior vena cava and so into the right heart. He did not make any blood-gas measurements.

Lauter (25), with Bauman and Friedländer, has investigated the volume output of the heart by actual puncture of the right ventricle and of an artery in man, and has found that the average arteriovenous oxygen difference under basal conditions in normal man is about 5 volumes per cent, and the average volume output of the heart about 4.5 liters per minute. This agrees satisfactorily with the results obtained by several of the indirect methods in the literature cited above. In general, certain foreign-gas inhalation methods appear to give values slightly lower than this, and certain Fick principle methods values somewhat higher; this work has been recently reviewed by Marshall (26).

Even after the direct determination of the $\mathrm{CO}_{2}$ and $\mathrm{O}_{2}$ in the blood from the right heart has been made, with the establishment of the accuracy, or the amount of error, of the indirect methods, these latter methods will probably continue to be used in experimental work, as 
one would expect that the obtaining of blood from the right heart will remain a somewhat formidable procedure.

It is of interest, therefore, to examine these methods as critically as possible, from the point of view of the assumptions implied in accepting their results.

The following are some of the more important assumptions usually made, explicitly or implicitly, in determinations of mixed venous values.

1. The actual procedure of rebreathing, etc., has no appreciable effect on the values obtained. This is not a simple question to decide. In the methods where several deep respirations are employed within a few seconds, the increased respiratory activity will increase the $\mathrm{CO}_{2}$ tension and decrease the $\mathrm{O}_{2}$ tension in the blood coming from these muscles; the "bellows" action of the chest will increase the rate of venous blood flow toward the heart, especially from the abdominal viscera. Whether this latter action will increase or decrease the "venosity" of mixed venous blood will perhaps depend largely on the state of the abdominal (especially liver) blood as compared to other venous blood.

On the other hand, in the methods where the breath is held for several seconds in inspiration, the effect will be to slow the general venous return, and there will be presumably less change in respiratory muscle activity.

The fact (17) that essentially the same mixed venous $\mathrm{CO}_{2}$ values are obtained whether the breath is held, or continuous rebreathing is employed, suggests that the resultant of the effects of this procedure does not involve a large error,-not more, probably, than $0.5 \mathrm{~mm}$. Such error as there is will be expected to make the $\mathrm{CO}_{2}$ tension as measured, higher than the actual resting mixed venous $\mathrm{CO}_{2}$ tension.

2. There is often assumed to be perfect mixture of all gases in the lungs, and between lungs and rebreathing bag. In earlier work this was taken for granted; more recently, Grollman and Marshall (21), also Bock, Dill and Talbott (17) have investigated this point, as noted above. This later work would seem to answer objections based on the possible disturbing effects due to the "fan-like" character of pulmonary expansion. 
3. The assumption is made that within the duration of these rebreathings (variously taken from 12 to 28 seconds) there is no appreciable amount of recirculating blood. The argument is made, reasonably enough, that if there were recirculating blood in progressively increasing quantities, there would be no "plateau" of equilibrium; as will be shown more fully later, however, a considerable amount of recirculating blood will cause only a slight upward trend to the $\mathrm{CO}_{2}$ plateau, and such a trend is present in most of the reported data. Thus there is good reason to suspect recirculation of the coronary blood. This error would make the mixed venous $\mathrm{CO}_{2}$ tension, as measured, something less than $0.5 \mathrm{~mm}$. above the actual mixed venous value.

4. It is assumed that the rebreathed air and the blood in the lungs are in perfect equilibrium in respect to $\mathrm{CO}_{2}$, and in respect to $\mathrm{O}_{2}$ also when true mixed venous tensions are being studied. When oxygenated venous values are being sought, it is assumed that equilibrium exists in respect to $\mathrm{CO}_{2}$ and that the blood hemoglobin is completely saturated with oxygen. This last point was demonstrated for the Field, Bock, et al. (16) method in two experiments by them, involving arterial punctures 20 seconds after rebreathing was begun. More recent work (27) from the same laboratory, however, suggests that even with hyperventilation and high alveolar $\mathrm{O}_{2}$ values, the arterial blood is rarely more than 97 per cent saturated. If this is the case, then the assumption of complete saturation involves a small error; this will make the oxygenated mixed venous $\mathrm{CO}_{2}$ tension, as measured, lower than the actual oxygenated mixed venous $\mathrm{O}_{2}$ tension.

The assumption of lung-blood equilibrium, so far as the true mixed venous blood (both a $\mathrm{CO}_{2}$ and $\mathrm{O}_{2}$ equilibrium) is concerned, has not previously been tested.

5. It is assumed that with the use of high oxygen mixtures to obtain oxygenated venous $\mathrm{CO}_{2}$ values, when a plateau of $\mathrm{CO}_{2}$ tension is reached, this will represent on the $\mathrm{CO}_{2}$ curve the true level of $\mathrm{CO}_{2}$ in the venous blood. There is a clear fallacy here, first pointed out to one of us several years ago by Dr. C. D. Murray. As oxygen is continually being absorbed, the total volume of rebreathed air is diminishing and $\mathrm{CO}_{2}$, therefore, becoming concentrated, and the final equilibrium value obtained for $\mathrm{CO}_{2}$ will be above that of the incoming venous 
blood. The extent of this effect will be shown by calculation presently to be in the region of $0.5 \mathrm{~mm}$.

It is not improbable that the effects described in paragraphs 4 and 5 tend to neutralize each other.

6. Most of the methods previously employed depend, for the demonstration of equilibrium values, upon successive rebreathing periods, usually four or more within 15 to 30 minutes. They thus assume a steady state in the subject's circulo-respiratory conditions. With trained subjects the constancy of results obtained would seem ample justification for this.

7. All of the methods based on the general technique of Henderson and Prince make the further assumption already referred to; namely that the diluting effect of the residual air in the lungs can always be compensated for by $\mathrm{CO}_{2}$ given off from the blood in the pulmonary vessels; and, therefore, that when the same value is reached, on successive rebreathings, this value represents the mixed venous level. That such an assumption is unwarranted has already been indicated. With a given constancy of technique, some constant value would always be reached eventually, whether this value had any relation to the mixed venous blood or not. Thus, suppose the following conditions: (a) air in bag 2,000 cc., containing $44 \mathrm{~mm} . \mathrm{CO}_{2}$; (b) residual air 1700 cc. containing $35 \mathrm{~mm}$. $\mathrm{CO}_{2} ;(c)$ oxygenated mixed venous tension $47 \mathrm{~mm} . \mathrm{CO}_{2} ;(d)$ and the amount of $\mathrm{CO}_{2}$ that can be given off into the lung air from the blood in 20 seconds as 20 cc. A simple calculation will show that when this bag mixture is rebreathed for 20 seconds, the final "equilibrium" value will always be $44 \mathrm{~mm} . \mathrm{CO}_{2}$ in the bag and lungs. (In this calculation, for purposes of simplification the effect of $\mathrm{O}_{2}$ absorption during the process is neglected.)

By altering the length of time of rebreathing, as Henderson and Prince (8) did, or by changing the mixture used, between rebreathings, as Field, Bock, et al. (16), and Bock, Dill, and Talbott (17) have done, this possible source of error can be investigated. It should be borne in mind, however, that this method may be applicable to some subjects and not to others. The subject of Hamilton, Moore and Kinsman's (23) experiments, for example, was apparently one of the latter. In general, those subjects with large arteriovenous differences, low circulation rates, and large residual air volumes relative to the volumes 
of air in the rebreathing bag, would be unfavorable types for these experimental methods.

8. It is a further assumption of all these methods, except those in which blood is drawn at the time of the experiment, and $\mathrm{CO}_{2}$ and $\mathrm{O}_{2}$ dissociation curves constructed, that although only gaseous tensions are measured, these can be translated into blood contents of $\mathrm{CO}_{2}$ or $\mathrm{O}_{2}$, by the use of standard dissociation curves.

It is clear, however, that for the purpose of obtaining arteriovenous differences, it is not necessary to suppose that the dissociation curves used are identical with that of the subject at the moment of rebreathing. In the case of oxygenated venous $\mathrm{CO}_{2}$ tensions, the slopes of the curves used, over the physiological range, must be the same as those of the subject's blood. In the case of true mixed venous tensions, both the slopes of the $\mathrm{CO}_{2}$ curves and the "spread" (distance between reduced and oxygenated curves) must be the same. These principles have been well recognized in recent years.

In sum, one can perhaps say that of these eight assumptions, those in paragraphs 1 and 3 are the most likely to be incorrect, and the least likely to be detected. The effect of respiratory movement and of recirculating blood would both act to make the mixed venous $\mathrm{CO}_{2}$ figures higher and circulation rate figures lower than the actual values; and the errors would be essentially the same by both Fick-principle and foreign-gas inhalation methods. The total error involved is probably less than 10 per cent of the arteriovenous difference.

In spite of this number of assumptions, most of the various methods used have given results for mixed venous tensions that are of the same order of magnitude,- an average level of from $45 \mathrm{~mm}$. to $50 \mathrm{~mm}$. of $\mathrm{CO}_{2}$ tension for most subjects. It is also true, however, that some methods, when used for the determination of circulation rate, give definitely higher values than other methods; some methods also give unexpectedly large variations in circulation rate for different normal individuals. These facts suggest that there may be with some methods a constant error; and that other methods may be applicable to some normal subjects, and not to certain others.

This brings us to a consideration of certain aspects of the problem of the equilibration of lung gases with incoming venous blood, which have thus far received relatively little attention. (a) Some work, 
as described, $(6,12,13)$ has been done in comparing one method with another; the greater part of this has been in comparisons of Fickprinciple with foreign-gas circulation rate methods. (b) There has been almost no work directed toward the determination of the limits of variation in composition of rebreathed mixtures, within which limits an apparent equilibrium with incoming blood can take place. And conversely, there has been a tendency to accept "plateau" or apparent equilibrium values as mixed venous values. (c) There has been relatively little study of the actual process of equilibration during the course of a single rebreathing technique.

Such studies should help to reveal the presence of false equilibrium values, or systematic differences of one method as compared with another.

In the experimental work which forms the second part of the present study, an attempt has been made to do these three things: (a) to compare three different methods, using the same subjects, these methods representing three different principles of equilibration; $(b)$ to follow the course of equilibration by samples taken every few seconds during the procedure; and $(c)$ (providing equilibrium levels are found) to determine the possible limits of composition of effective rebreathing mixtures.

At this point in the discussion, it may make for greater clearness if we endeavor to describe what may be expected to take place in the lungs during the course of this process of equilibration. The major variables in the process are familiar, and it should be possible to arrive at a fairly accurate and complete description.

I. Consider first the situation when "true" mixed venous equilibrium is being investigated; that is, when lung air is brought into equilbrium with both the $\mathrm{CO}_{2}$ and the $\mathrm{O}_{2}$ tensions of the incoming venous blood.

Take certain typical values for the various factors concerned, as shown in table 1 (many of these from an actual experiment on subject D. W. R.).

In this table it will be seen that various assumptions, as previously outlined, have been made.

A. In the first instance, suppose that, after the rebreathing of the mixture has been completed in (say) 15 seconds, (a) mixture of gases is complete, and $(b)$ initial tensions have been such that, when mixture 
is effected, $\mathrm{O}_{2}$ and $\mathrm{CO}_{2}$ tensions in the lung air will be the same as those of the incoming blood.

In the situation as above defined, certain points are to be noted:

1. Equilibrium will have had to be established, not only between lung air and blood, but between lung air and lung tissue fluids as well. Much of this tissue fluid is presumably in equilibrium with residual (alveolar) air. The initial mixture in the bag must, therefore, have had a certain excess of $\mathrm{CO}_{2}$ and deficit of $\mathrm{O}_{2}$, in order to provide for the change of tissue fluid tension from alveolar to venous levels.

2. Equilibrium, even if it is established between lungs and blood, will not remain absolutely perfect because $\mathrm{N}_{2}$ will tend to diffuse into

TABLE 1

Tensions of respired gases in atmospheric air, lungs, and blood with subject breathing atmospheric air

Volume of residual air in lungs $=1,700 \mathrm{cc}$.

Volume of air in rebreathing bag $=2,500 \mathrm{cc}$.

Circulation rate per minute $=4,400 \mathrm{cc}$.

Barometric pressure $=755.0 \mathrm{~mm}$.

\begin{tabular}{|c|c|c|c|c|c|}
\hline Units & $\begin{array}{l}\text { Outside } \\
\text { air (dry) }\end{array}$ & $\begin{array}{l}\text { Alveolar } \\
\text { air (= } \\
\text { residual) }\end{array}$ & $\begin{array}{c}\text { Arterial } \\
\text { blood }\end{array}$ & $\begin{array}{l}\text { Mixed } \\
\text { venous } \\
\text { lung } \\
\text { tensions }\end{array}$ & $\begin{array}{l}\text { Mixed } \\
\text { venous } \\
\text { blood } \\
\text { tensions }\end{array}$ \\
\hline Oxygen, mm. . & 158.5 & 93.0 & 80.0 & 40.0 & 40.0 \\
\hline $\mathrm{CO}_{2}, \mathrm{~mm} . \ldots$ & 0.2 & 44.6 & 44.6 & 49.8 & 49.8 \\
\hline$\ldots \ldots \ldots \ldots \ldots \ldots \ldots \ldots \ldots$ & 596.3 & 569.4 & 569.4 & 617.2 & 569.4 \\
\hline Water, mm.................... & 0.0 & 48.0 & 48.0 & 48.0 & 48.0 \\
\hline Total, mm.. & 755.0 & 755.0 & 742.0 & 755.0 & 707.2 \\
\hline
\end{tabular}

venous blood, thus concentrating the lung air with respect to its other gases; therefore, a little more $\mathrm{O}_{2}$ and $\mathrm{CO}_{2}$ will diffuse into the blood to reestablish equilibrium. On account of the small solubility of $\mathrm{N}_{2}$ gas in blood, this effect is negligible.

3 . With the exception just mentioned, a nearly exact correspondence will be expected to exist between lung and blood gases, once equilibrium has been established, until appreciable amounts of blood begin to recirculate.

B. In the next situation to be considered, suppose the same general conditions as under $A$, with the further feature that a certain fraction of the blood flow has recirculated within the first 4 or 5 seconds, and 
continued to do so, without any other fractions of the blood recirculating for an ensuing 10 or 15 seconds. Can a new equilibrium be obtained? In order for this to be so, it will theoretically be necessary (a) for the true venous blood to pass through the lungs unchanged (lungs at mixed venous tensions), (b) for part of this blood to recirculate through the short-circuit path (thus gaining an added increment of $\mathrm{CO}_{2}$ and losing $\mathrm{O}_{2}$ ), (c) for the new mixed venous blood (contaminated by recirculation) to make a further course through the lungs and reestablish a new venous level. Even then the new equilibrium would not be quite complete. There is no use in trying to reason too closely upon this point. It is clear that with recirculation of appreciable amounts of blood, exact plateau or equilibrium levels will not be obtained. Small amounts of blood can readily recirculate, however, without detection by present experimental methods. Thus, simple calculation will show that if there is recirculation of as much as 10 per cent of the minute volume, this will in ordinary conditions at rest, change the "equilibrium" mixed venous value by $0.5 \mathrm{~mm}$. of $\mathrm{CO}_{2}$ or less.

C. Assume that the air in the bag is such that upon mixture with residual air in the lungs, the gases are not in equilibrium with the incoming blood. The questions that arise are: $(a)$ how nearly, at any instant, will the lung tensions be in equilibrium with the outgoing arterial (i.e., pulmonary vein) blood-i.e., is there a lag in equilibration between lungs and blood? (b) How large a discrepancy can there be at the beginning of rebreathing between mixed lung air, and venous blood, and still have enough $\mathrm{CO}_{2}$ and $\mathrm{O}_{2}$ absorbed into or given off from the blood within 15 to 20 seconds so as to reach equilibrium?

(a) The answer to this question could perhaps be predicted on the basis of diffusion rates of gases in pulmonary alveoli, but too little is known of these conditions to admit of even approximate estimates. The question must be decided by experiment. From an experiment which we report in detail in the subsequent part, it seems clear that for both $\mathrm{CO}_{2}$ and $\mathrm{O}_{2}$ in the tensions near the mixed venous values, equilibrium between lungs and blood is nearly complete at the end of the twentieth second of rebreathing.

(b) If we suppose, then, on the basis of the above mentioned experiment, that lungs and blood are in approximate equilibrium, it 
becomes possible to determine from a blood nomogram the amounts of $\mathrm{CO}_{2}$ and of $\mathrm{O}_{2}$ that will be available from the blood, or else the amounts which the blood can be expected to absorb, when the lung gases have not the same tensions as the incoming venous blood.

Supposing the same general circulatory conditions as given above, how much $\mathrm{O}_{2}$ and $\mathrm{CO}_{2}$ will be available in 15 or 20 seconds if the mixed lung gases $\left(\mathrm{CO}_{2}\right.$ and $\left.\mathrm{O}_{2}\right)$ at the outset are $5 \mathrm{~mm}$. lower than the venous gases; and how nearly will equilibrium be reached within this time? Conditions at the start will be as in table 2 (column 3 here is the same as column 6 of table 1 , column 2 gives the assumed initial lung tensions).

Presumably, equilibrium between lung air and incoming blood in the alveoli will be approached asymptotically. We have not attempted

TABLE 2

Tensions of respired gases in low $\mathrm{O}_{2}-\mathrm{CO}_{2}$ rebreathing mixture compared with tensions in normal venous blood

\begin{tabular}{|c|c|c|}
\hline & $\begin{array}{l}\text { Initial mixed lung } \\
\text { tensions }\end{array}$ & $\begin{array}{l}\text { Mixed venous blood } \\
\text { tensions }\end{array}$ \\
\hline Oxygen, $\operatorname{mm} . \ldots \ldots \ldots \ldots \ldots \ldots \ldots \ldots \ldots$ & 35.0 & 40.0 \\
\hline 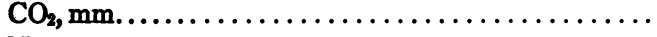 & 44.8 & 49.8 \\
\hline 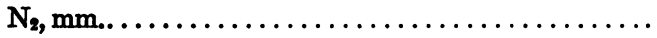 & 627.2 & 569.4 \\
\hline Water, $\operatorname{mm} . . \ldots \ldots \ldots \ldots \ldots \ldots \ldots \ldots \ldots \ldots \ldots \ldots \ldots$ & 48.0 & 48.0 \\
\hline Total, $\mathrm{mm} . \ldots \ldots \ldots \ldots \ldots \ldots \ldots$ & 755.0 & 707.2 \\
\hline
\end{tabular}

an integral expression for this change, but have assumed the pressure gradient to remain constant over 1 second intervals and in the case of the $\mathrm{CO}_{2}$, have calculated the $\mathrm{CO}_{2}$ tension in the lungs at each particular second by adding to the initial amount of $\mathrm{CO}_{2}$ in the lungs, the sum of the amounts of this gas contributed from the blood during each of the preceding seconds, then dividing this number by the total volume of lung-bag air and multiplying by the barometric pressure. The difference between the lung tension thus calculated and the mixed venous $\mathrm{CO}_{2}$ tensions then gives the pressure gradient for that particular second of time.

By this calculation, it is found that at the end of 15 seconds, the $\mathrm{CO}_{2}$ tension in the lung-bag system will be $47.8 \mathrm{~mm}$., still $2 \mathrm{~mm}$. below the 
mixed venous level, and at the end of 20 seconds $48.4 \mathrm{~mm}$., or $1.4 \mathrm{~mm}$. below equilibrium.

For oxygen, the values at the end of 15 and 20 seconds will be even further from equilibrium because the dissociation curve is flatter than the $\mathrm{CO}_{2}$ dissociation curve, that is, a smaller volume of oxygen is given off from the blood per millimeter of pressure difference, than of $\mathrm{CO}_{2}$.

It may be added here parenthetically that a simpler and sufficiently

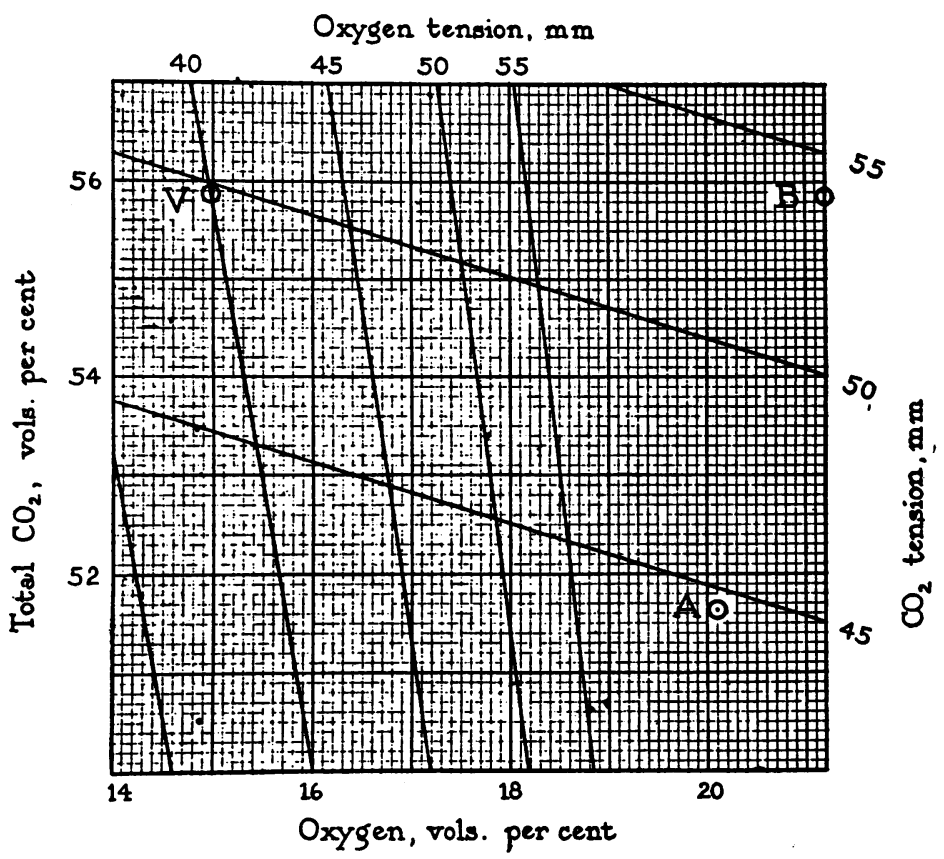

Fig. 1. $\mathrm{CO}_{2}-\mathrm{O}_{2}$ Nomogram of SubJect D. W. R.

$A$, arterial blood; $V$, mixed venous blood; $B$, oxygenated mixed venous blood

accurate method for making this calculation is by assuming over the whole 20 seconds of rebreathing a constant average pressure gradient, namely half the initial pressure difference between lung-bag air and blood, or $2.5 \mathrm{~mm}$. for both $\mathrm{CO}_{2}$ and $\mathrm{O}_{2}$. In this region of the nomogram (fig. 1), $1 \mathrm{~mm}$. change of $\mathrm{CO}_{2}$ tension at constant oxygen tension corresponds to $0.51 \mathrm{cc} . \mathrm{CO}_{2}$ (under standard temperature and barometer conditions); and $1 \mathrm{~mm}$. of change of $\mathrm{O}_{2}$ tension at constant 
$\mathrm{CO}_{2}$ tension, to $0.23 \mathrm{cc}$. $\mathrm{O}_{2}$. In 20 seconds, there will be $2.5 \times 0.51 \times$ $20 \times \frac{4400}{60 \times 100} \times \frac{273+38}{273}=21.4$ cc. of $\mathrm{CO}_{2}$ given off by the blood (at $38^{\circ} \mathrm{C}$.) and $2.5 \times 0.23 \times 20 \times \frac{4400}{60 \times 100} \times \frac{273+38}{273}=9.6 \mathrm{cc}$. of $\mathrm{O}_{2}$. The $21.4 \mathrm{cc}$. of $\mathrm{CO}_{2}$ would raise the $\mathrm{CO}_{2}$ tension from 44.8 to $\left\{\left[\left(\frac{44.8}{755} \times 4200\right)+21.4\right] \div 4231\right\} \times 755=48.4 \mathrm{~mm}$.; and the $9.6 \mathrm{cc}$. of $\mathrm{O}_{2}$ would raise its tension from $35 \mathrm{~mm}$. to $\left\{\left[\left(\frac{35}{755} \times 4200\right)+\right.\right.$ $9.6] \div 4231\} \times 755=36.6 \mathrm{~mm}$.

These estimates are naturally only first approximations, but it is clear that, in order for equilibrium to be obtained by this method between lungs and blood within 20 seconds, the differences in tension between the gas tensions of lungs and blood, at the start of equilibration must be small; less than $5 \mathrm{~mm}$. for $\mathrm{CO}_{2}$ and considerably less than this for $\mathrm{O}_{2}$. In the experiments reported in the subsequent part, this conclusion will be verified.

II. In the case where oxygenated mixed venous blood is being studied, a further set of typical values will be useful (table 3).

A. Again we assume here that mixture is complete, and, in the first instance, that the tensions in lungs and bag are such that when mixture has been effected, and incoming blood has been completely oxygenated, then the $\mathrm{CO}_{2}$ tension in lung air and incoming blood will be the same. In other words, there will be no net change of the $\mathrm{CO}_{2}$ of the blood during its passage through the lungs. During the first part of the length of the alveolar capillary, while the blood is still partly unsaturated with $\mathrm{O}_{2}$, there will be a small temporary inflow of $\mathrm{CO}_{2}$, which will leave the blood again as arterialization is completed. This transient process is here disregarded.

In this instance, however, it becomes necessary to investigate the effect (already referred to above), of $\mathrm{O}_{2}$ absorption by the blood, and consequent concentration of other lung gases, upon the general equilibrium values.

By reference to the $\mathrm{CO}_{2}-\mathrm{O}_{2}$ nomogram, figure 1 , it is found that the normal venous blood of $\mathrm{D}$. W. R. with an $\mathrm{O}_{2}$ tension of $40 \mathrm{~mm}$., 
and $\mathrm{CO}_{2}$ tension of $50 \mathrm{~mm}$., contains $15.0 \mathrm{cc}$. of $\mathrm{O}_{2}$ per $100 \mathrm{cc}$. of blood. The oxygenated blood leaving the lungs after rebreathing the high $\mathrm{O}_{2}$ mixture will be (it is assumed) completely saturated (Field, Bock, et al. (16)), and will in this case contain $21.2 \mathrm{cc}$. of $\mathrm{O}_{2}$ per $100 \mathrm{cc}$. of blood. About $6.2 \mathrm{cc}$. of $\mathrm{O}_{2}$ will, therefore, be absorbed per $100 \mathrm{cc}$. of blood flowing. In 20 seconds, with a minute volume of circulation of 4400 cc. this will amount to $44 \times \frac{20}{60} \times 6.2=91 \mathrm{cc}$. of $\mathrm{O}_{2}$ absorbed. This latter figure represents $\mathrm{O}_{2}$ under standard temperature and bar-

\section{TABLE 3}

Comparison of tensions of respired gases in (a) atmospheric (outside) air, (b) alveolar air, (c) arterial blood, (d) and (e) lungs and blood in "oxygenated mixed venous" equilibrium

Volume of residual air in lungs $=1,700 \mathrm{cc}$.

Volume of air in rebreathing bag $=2,500 \mathrm{cc}$.

Circulation rate per minute $=4,400 \mathrm{cc}$.

Barometric pressure $=755 \mathrm{~mm}$.

\begin{tabular}{|c|c|c|c|c|c|}
\hline . & $\begin{array}{l}\text { Outside air } \\
\text { (dry) }\end{array}$ & $\begin{array}{c}\text { Alveolar } \\
\text { air }(= \\
\text { residual })\end{array}$ & $\begin{array}{c}\text { Arterial } \\
\text { blood }\end{array}$ & $\begin{array}{c}\text { Oxygen- } \\
\text { ated mixed } \\
\text { venous } \\
\text { lung } \\
\text { tensions }\end{array} \mid$ & $\begin{array}{l}\text { Oxygen- } \\
\text { ated mixed } \\
\text { venous } \\
\text { blood } \\
\text { tensions }\end{array}$ \\
\hline 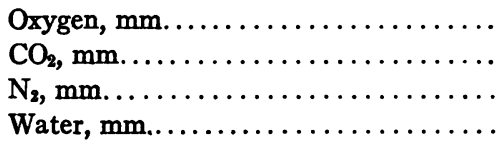 & $\begin{array}{r}158.5 \\
0.2 \\
596.3 \\
0.0\end{array}$ & $\begin{array}{r}93.0 \\
44.6 \\
569.4 \\
48.0\end{array}$ & $\begin{array}{r}80.0 \\
44.6 \\
569.4 \\
48.0\end{array}$ & $\begin{array}{r}100+ \\
54.0 \\
553- \\
48.0\end{array}$ & $\begin{array}{r}100 \pm \\
54.0 \\
553 \pm \\
48.0\end{array}$ \\
\hline Total, $\mathrm{mm} .$. & 755.0 & 755.0 & 742.0 & 755.0 & 755(?) \\
\hline
\end{tabular}

ometric conditions: 91 cc. $\times \frac{273+38}{273}=104 \mathrm{cc}$. of lung-bag oxygen absorbed. This will change the $\mathrm{CO}_{2}$ tension in lung-bag system from its initial value of $\frac{300}{4200} \times 755=54.0 \mathrm{~mm}$. to $\frac{300}{4096} \times 755=55.3 \mathrm{~mm}$.

The ultimate effect will be less than this, because the extra $\mathrm{CO}_{2}$ will redistribute itself between lungs and blood, and much of it, therefore, will be carried away in the blood as fast as it accumulates. As an approximation, we may suppose an average $\mathrm{CO}_{2}$ tension gradient between lungs and blood (due to oxygen absorption), of $\frac{55.3-54.0}{2}=$ 
$0.65 \mathrm{~mm}$. Then in 20 seconds, $0.65 \times 0.51 \times \frac{4400}{300}=4.9 \mathrm{cc}$. of $\mathrm{CO}_{2}$ reabsorbed. Thus the final lung-bag tension of $\mathrm{CO}_{2}$ at the end of 20 seconds will be approximately $\frac{300-4.9}{4096} \times 755=54.4 \mathrm{~mm}$.

In summary, therefore, this concentration effect is not quite negligible; it should cause the oxygenated mixed venous tensions of $\mathrm{CO}_{2}$, at the end of 20 seconds rebreathing, to be in the region of $0.4 \mathrm{~mm}$. higher than the true equilibrium value; and it should further provide that, even if this true equilibrium value is attained at any moment, the $\mathrm{CO}_{2}$ tension will thereafter show a small steady rise, instead of remaining perfectly constant. This latter effect would be small, however, and by itself would probably escape detection with present methods of analysis.

If, as suggested above, the oxygenated mixed venous blood is actually not more than 97 per cent saturated, it can readily be seen that the errot involved in assuming complete oxygenation will tend to counteract the error due to neglecting the oxygen absorption effect.

B. Assume in this instance that lung-bag air (after mixture) is such that upon oxygenation of the blood, the tension of the $\mathrm{CO}_{2}$ in the blood thus oxygenated is less than the $\mathrm{CO}_{2}$ tension in lung-bag air. $\mathrm{CO}_{2}$ will pass from lungs into blood. The question arises, how much of an excess of $\mathrm{CO}_{2}$ can exist in lung-bag air, and still reach an equilibrium with the incoming venous blood at the end of 20 seconds? How much extra $\mathrm{CO}_{2}$ can the blood absorb?

The attempt to calculate how much $\mathrm{CO}_{2}$ will be absorbed into the blood, with a given $\mathrm{CO}_{2}$ tension difference between blood and lung-bag air, raises the further question as to how complete is the equilibrium between lungs and (oxygenated) alveolar blood, with respect to $\mathrm{CO}_{2}$. In the region of the tensions of oxygenated mixed venous blood this equilibrium has been shown by Field, Bock, et al. (16), to be nearly complete; rebreathed air samples having been compared with simultaneously drawn arterial blood. It is, therefore, again possible to determine from a blood nomogram, or from a $\mathrm{CO}_{2}$ dissociation curve of arterial blood, approximately the amounts of $\mathrm{CO}_{2}$ that can be absorbed in a given interval.

In this calculation account must be taken of the oxygen absorbed 
from lung-bag air during the interval. Taking the same basic figures, we have $104 \mathrm{cc}$. of $\mathrm{O}_{2}$ absorbed in 20 seconds, out of a total of lung-bag volume of $4200 \mathrm{cc}$.

Suppose that the lung-bag mixture is $2 \mathrm{~mm}$. higher in $\mathrm{CO}_{2}$ tension than that of the oxygenated mixed venous blood. Take the same figures as before for volumes, blood gas tensions, blood flow, etc.

At the start of rebreathing, the lungs will contain $\frac{56}{755} \times 4200=312$ cc. of $\mathrm{CO}_{2}$. In 20 seconds $\frac{4400}{3}$ cc. of blood will flow. For every $1 \mathrm{~mm}$. change in $\mathrm{CO}_{2}$ tension, $0.46 \mathrm{cc}$. of $\mathrm{CO}_{2}$ will be absorbed per $100 \mathrm{cc}$. blood (see nomogram, from $50 \mathrm{~mm}$. to $55 \mathrm{~mm}$. $\mathrm{CO}_{2}$ tension on completely oxygenated line). With an average pressure head of $1.5 \mathrm{~mm}$. the $\mathrm{CO}_{2}$ absorbed in 20 seconds will be $\frac{4400}{300} \times 0.46 \times 1.5=10.1$ cc. $312-10.1=302 \mathrm{cc}$. of $\mathrm{CO}_{2}$ remaining in lung-bag air. The volume of this air will now be $4200-104-10.1=4086$ because of loss of $\mathrm{O}_{2}$ and $\mathrm{CO}_{2}$. The final $\mathrm{CO}_{2}$ tension will, therefore, be $\frac{302}{4086} \times 755=$ $55.8 \mathrm{~mm}$. In other words, even with the small excess of $2 \mathrm{~mm}$. of lung-bag $\mathrm{CO}_{2}$ tension, equilibrium cannot theoretically be reached with the incoming venous blood, within 20 seconds. This calculation is admittedly approximate and several small corrections that might be made have been omitted, but the tentative conclusion that it leads to seems unmistakable.

A similar calculation for an excess of $5 \mathrm{~mm}$. in lung-bag mixture (initial $\mathrm{CO}_{2}$ tension of $59 \mathrm{~mm}$.) leads to a final $\mathrm{CO}_{2}$ tension (at the end of 20 seconds) of $57 \mathrm{~mm}$.; and an initial excess of $10 \mathrm{~mm}$. of $\mathrm{CO}_{2}(64 \mathrm{~mm}$. tension) gives a tension after 20 seconds of $58.5 \mathrm{~mm}$. Thus it is evident that with increasing excesses of $\mathrm{CO}_{2}$ in the lung-bag air, the final values at the end of rebreathing steadily, though quite gradually, rise above the tensions of $\mathrm{CO}_{2}$ of oxygenated mixed venous blood. This type of change will be apparent in the experimental data given later.

It should be noted that in the preceding comments no account has been taken of the buffering effect, so to speak, of the lung tissues themselves. These tissues will, for the most part, presumably be near the gaseous tensions of the alveolar air, and will, therefore, absorb certain 
amounts of $\mathrm{CO}_{2}$ when equilibrium with mixed venous tensions is being approached. It would be difficult to assign any values to the amounts of $\mathrm{CO}_{2}$ thus absorbed.

C. Finally, it is necessary to consider the case in which the lung-bag mixture is lower in initial $\mathrm{CO}_{2}$ tension than the oxygenated mixed venous blood. As pointed out above, most of the methods used hitherto, and all of those based on the Henderson-Prince technique, are in this class, the equilibrium values for $\mathrm{CO}_{2}$ tension being approached from below. What is the lowest initial $\mathrm{CO}_{2}$ tension that may be used and still establish equilibrium with the incoming venous blood before recirculation?

Again let us take the same physiological values as before. Suppose the lung-bag mixture to be $4 \mathrm{~mm}$. lower in $\mathrm{CO}_{2}$ tension than the oxygenated mixed venous tension, that is, $50 \mathrm{~mm}$. At the start, in the lung-bag space there will be $\frac{50}{755} \times 4200=278 \mathrm{cc}$. $\mathrm{CO}_{2}$. In 20 seconds approximately $\frac{54-50}{2} \times \frac{4400}{300} \times 0.46=13.5 \mathrm{cc}$. of $\mathrm{CO}_{2}$ (standard conditions) will be given off from the blood; this at lung temperature will be about $\frac{311}{273} \times 13.5=15.4 \mathrm{cc}$. The $\mathrm{CO}_{2}$ tension in the lung-bag mixture after rebreathing will, therefore, be $\frac{278+15.4}{4200-104+15.4} \times 755$ $=53.9 \mathrm{~mm}$. This is practically the actual oxygenated mixed venous $\mathrm{CO}_{2}$ tension.

If the initial lung-bag mixture were $6 \mathrm{~mm}$. too low in $\mathrm{CO}_{2}$ tension, then the value after rebreathing would be $53.2 \mathrm{~mm}$., or $0.8 \mathrm{~mm}$. below equilibrium value.

Again no account has been taken of the effect of the lung tissues, which will require certain extra amounts of $\mathrm{CO}_{2}$ to raise them to oxygenated mixed venous levels.

Thus, under the conditions here postulated, the lowest possible value of initial lung-bag $\mathrm{CO}_{2}$ tension, that can be equilibrated with the venous blood within 20 seconds will be a tension somewhat less than $4 \mathrm{~mm}$. below the oxygenated mixed venous tension.

Now apply this same type of calculation to an experimental method 
in which successive rebreathing periods are employed. Supposing that following a certain period of rebreathing, an equilibrium with the oxygenated mixed venous blood is reached, with respect to $\mathrm{CO}_{2}$; in the next period will the dilution due to residual alveolar air be made up by $\mathrm{CO}_{2}$ given off from the blood?

Take for the purpose a series of actual data from subject D. W. R.:

Alveolar $\mathrm{CO}_{2}$ tension $43.9 \mathrm{~mm}$.

Oxygenated mixed venous $\mathrm{CO}_{2}$ tension $53.3 \mathrm{~mm}$.

Residual air $2,000 \mathrm{cc}$. containing $\frac{43.9}{755} \times 2,000=116 \mathrm{cc}$. $\mathrm{CO}_{2}$.

Air in bag $2,500 \mathrm{cc}$. containing $\frac{53.3}{755} \times 2500=176 \mathrm{cc}$. $\mathrm{CO}_{2}$.

Lung-bag tension at start of rebreathing $\frac{116+176}{2000+2500} \times 755=49.0 \mathrm{~mm} . \mathrm{CO}_{2}$.

Circulation rate per minute $=5100 \mathrm{cc}$. per minute.

$\mathrm{CO}_{2}$ available from blood (see above):

$$
\frac{53.3-49.0}{2} \times \frac{1700}{100} \times 0.46 \times \frac{311}{273}=19.2 \mathrm{cc} \text {. in } 20 \text { seconds. }
$$

$14.4 \mathrm{cc}$. in 15 seconds.

Total air in lung-bag system after 20 seconds:

$4500+19.2-120=4399 \mathrm{cc}$. (120 cc. of $\mathrm{O}_{2}$ absorbed in 20 seconds).

After 15 seconds, $4500+14.4-90=4424$.

Final $\mathrm{CO}_{2}$ tension after rebreathing:

$$
\begin{aligned}
& \frac{292+19.2}{4399} \times 755=53.4 \mathrm{~mm} . \text { at end of } 20 \text { seconds. } \\
& \frac{292+14.4}{4424} \times 755=52.4 \mathrm{~mm} . \text { at end of } 15 \text { seconds. }
\end{aligned}
$$

In this case, then, there is just enough $\mathrm{CO}_{2}$ available to return the tension to its former value after 20 seconds' rebreathing, providing no account is taken of absorption of $\mathrm{CO}_{2}$ by lung tissue fluids. If this is appreciable, then the values of $\mathrm{CO}_{2}$ reached by successive rebreathings for 20 seconds will not represent the actual mixed venous level. Still further deviations will occur if $(a)$ the residual air is greater in volume relative to the air in the bag, (b) blood flow is slower, and (c) arteriovenous difference is greater. It will, therefore, be clear that for a technique of this sort, the actual mixed venous value may be obtained with one subject and not obtained with another. 
SUMOMARY

Preliminary to some experimental studies upon the mixed venous blood values of man at rest, the previous literature has been reviewed, with special emphasis upon the inferential nature of the results obtained, and the numerous assumptions involved.

Certain aspects of the process of equilibration of lung gases with incoming venous blood, are discussed.

\section{PART II}

\section{EXPERIMENTAL}

In the first part of the present investigation we have reviewed the previous work on this subject, discussed some of the assumptions upon which the measurements of mixed venous blood in man are based, and described what we conceived to be the probable sequence of events within the lungs when the rebreathing procedures were carried out under various conditions.

In our experimental work, we have attempted to study further the process whereby equilibrium between lung air and incoming venous blood is reached; specifically to find answers to the following questions:

1. Is a "plateau" or apparent equilibrium level in rebreathed lung gases demonstrable over an appreciable length of time, before evidence of recirculating blood is manifest?

2. If such an apparent equilibrium between respired gases and incoming blood is reached, how soon after beginning rebreathing can this be demonstrated, how long does it last, how soon do signs of recirculation of blood appear and how rapidly does this recirculating blood change the apparent equilibrium values?

3. What are the upper and lower limits of respired air mixtures, within which limits an apparent equilibrium can be reached before recirculation of blood occurs?

4. Are oxygenated mixed venous values comparable with actual or true mixed venous values?

5. Do the methods of intermittent rebreathings (without changing the gas in the bag between periods) give the same values as methods using only a single rebreathing period? 
6. Are lungs and arterial blood in equilibrium during the rebreathing procedures (only a partial answer attempted)?

The experimental studies which we have made fall under three general headings:

(a) The equilibrium in the case of oxygenated mixed venous tensions, during a single rebreathing period.

(b) The same, studied during intermittent rebreathing periods, with intervals of rest between, and without changing the gases in the rebreathing bag in these intervals.

(c) The equilibrium in the case of the actual mixed venous tensions (equilibrated both with $\mathrm{CO}_{2}$ and $\mathrm{O}_{2}$ ), during a single rebreathing period. Each of these determinations was always either preceded or followed by an equilibration with oxygenated tensions (group (a) above), for purposes of comparison.

Two normal subjects were used, M. L. S. and D. W. R., a considerable number of experiments having been performed with the latter, and a smaller number-with the major purpose of confirming the general findings on D. W. R.-with the former subject. A few relevant data regarding the two subjects are listed in tables 4 and 5 .

It is evident that for the purposes of this study it was important to have as many observations as possible taken during the course of a single rebreathing period; this was done by the use of a series of evacuated gas sampling tubes, either six or nine being used to give the corresponding number of separate samples during the experimental period of from 25 to 50 seconds.

\section{METHODS}

In further detail, the methods used were as follows:

(a) For oxygenated mixed venous tensions, the simple apparatus shown in figure 2 was employed. Most of the experiments were done toward the end of the morning, the subject having had an ordinary breakfast three or four hours before. A few were done in mid-afternoon, two or three hours after lunch. After 15 minutes to half an hour of rest in the horizontal position, the subject applied mouthpiece and noseclip and respired through the apparatus for five to ten minutes. At the end of this time, at the signal "Blow," given at the end of a normal expiration, the subject expired completely while slide valve $B$ was closed off. At the end of this expiration an alveolar air sample was (usually) taken into one of the sampling tubes. After a rest interval of three minutes, a similar complete expiration was 


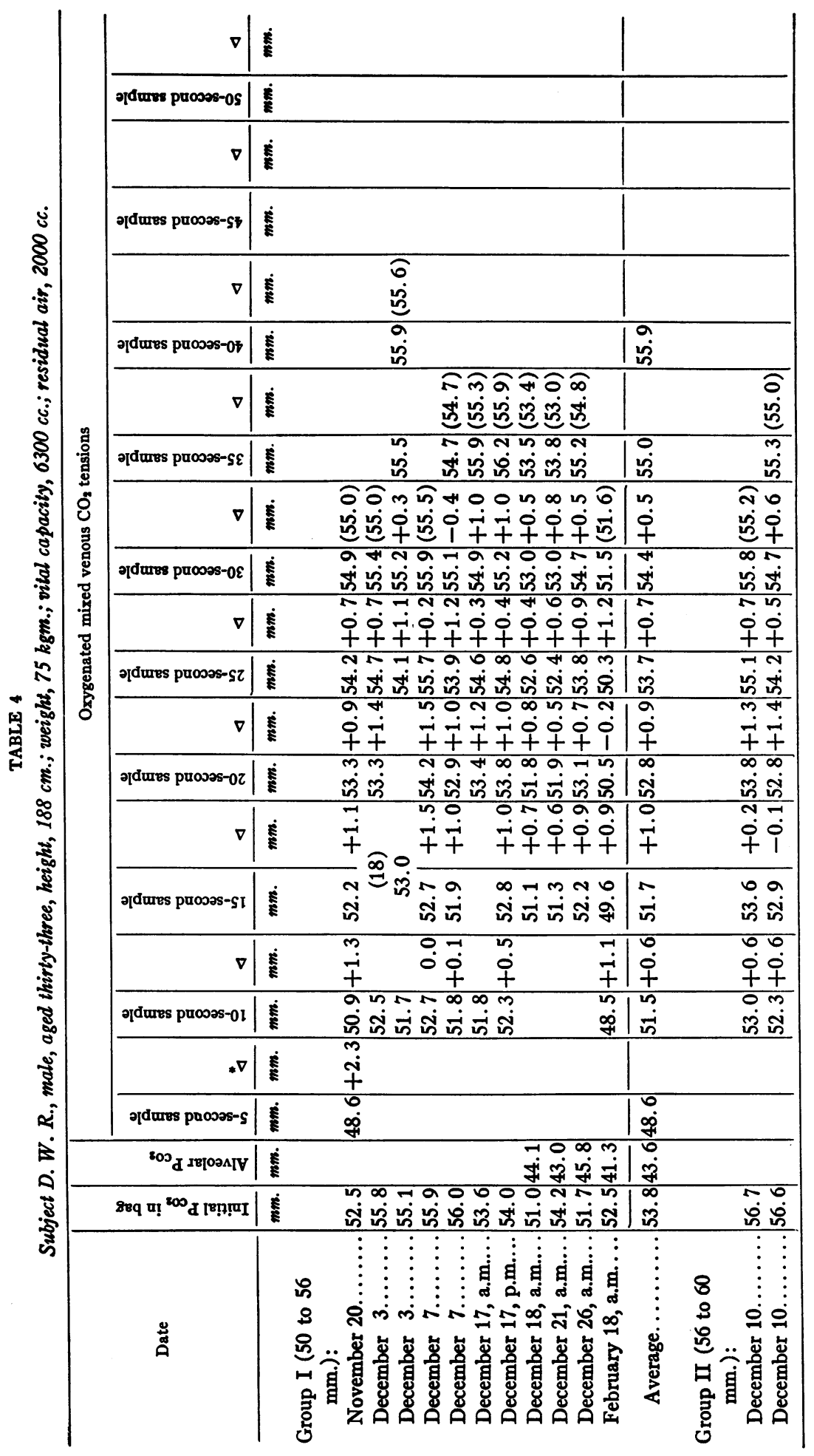




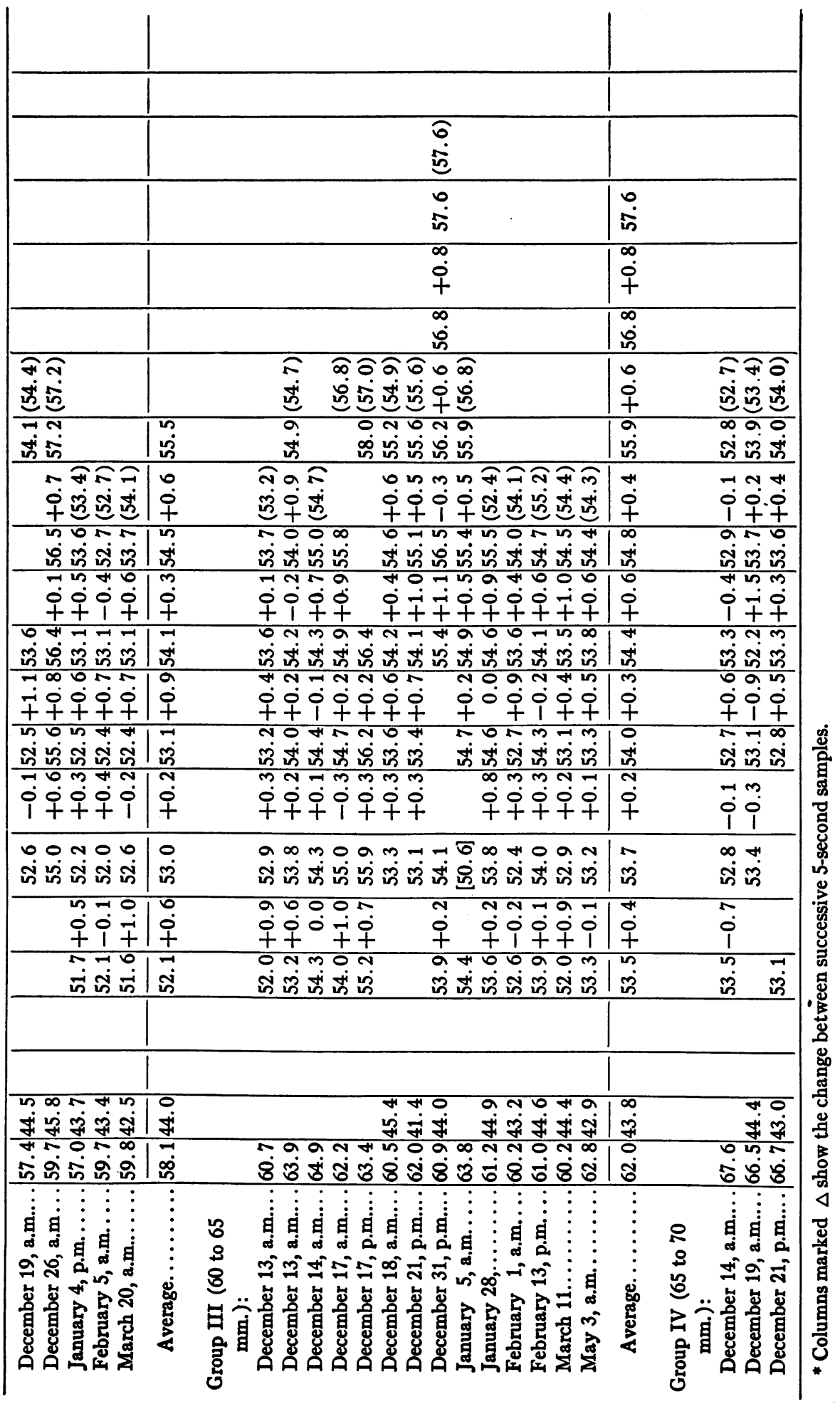




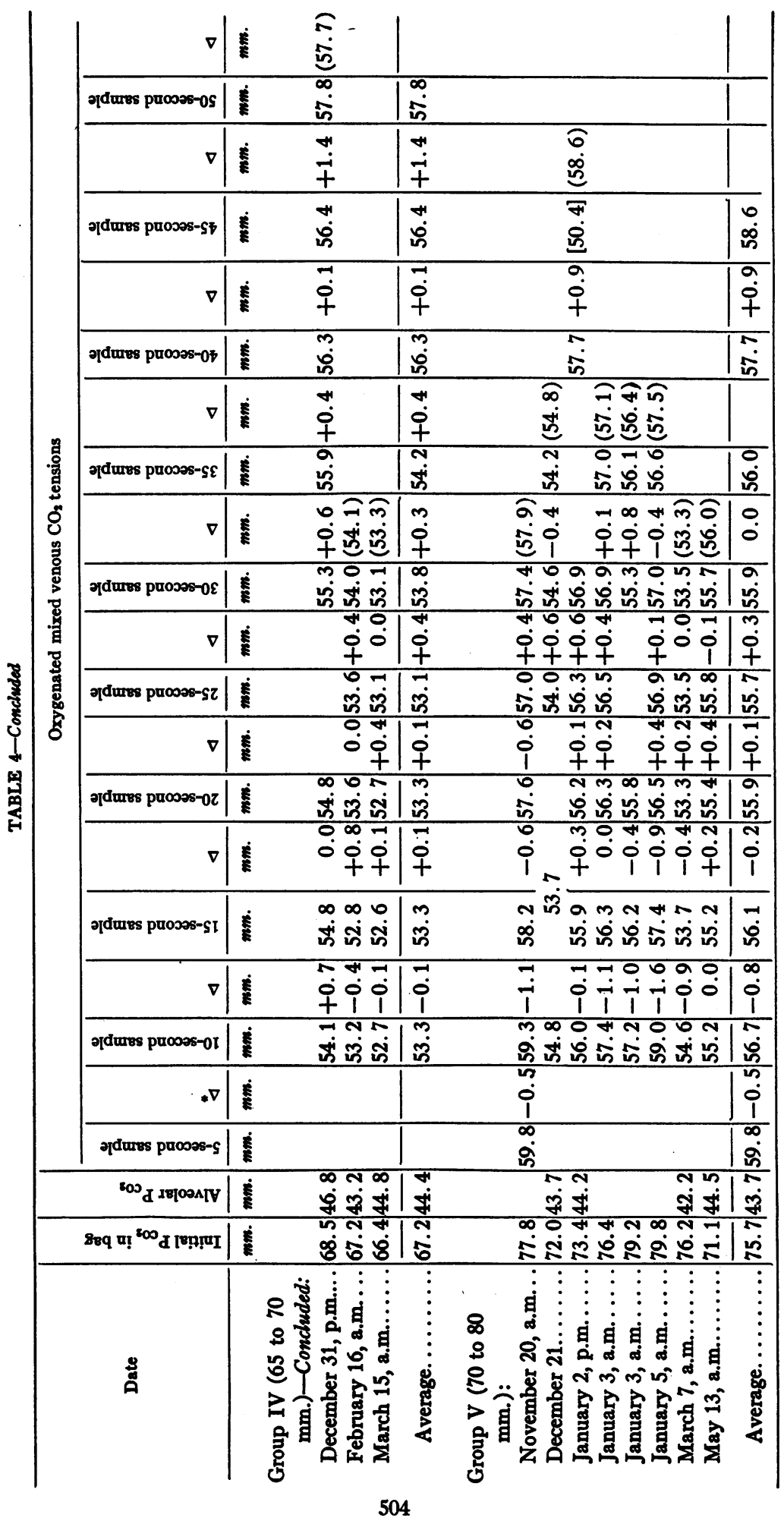


DICKINSON W. RICHARDS, JR., AND MARJORIE L. STRAUSS

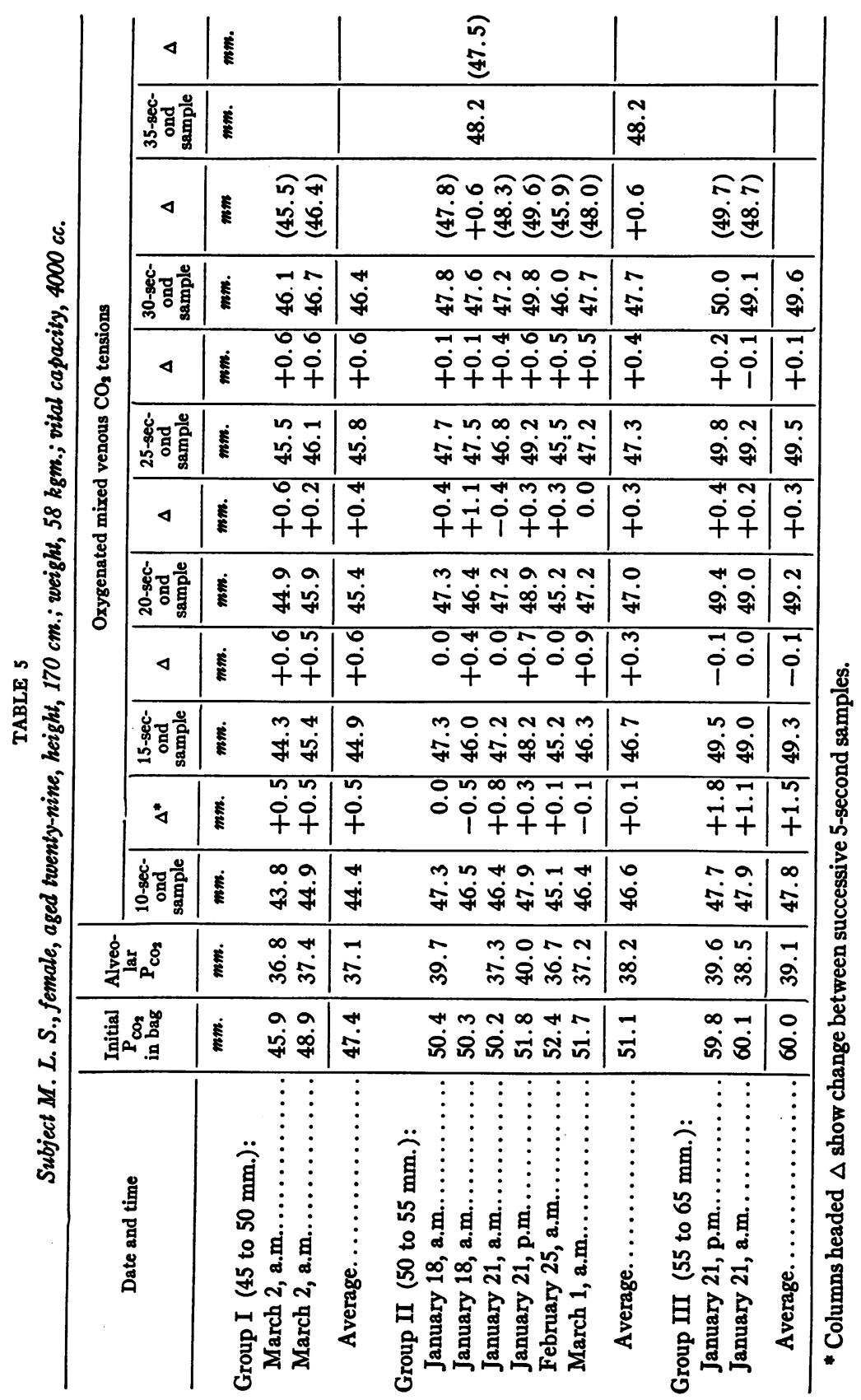


made at the "Blow" signal, the slide valve shut down as before, and the 3 way valve turned so as to connect the rebreathing bag with the subject. The subject then emptied and filled the bag completely, by successive respirations, samples being taken into the sampling tubes every 5 seconds at the end of a complete expiration. At first a complete respiration was made every $2 \frac{1}{2}$ seconds (subject timing his breathing with the aid of a stop watch, starting the watch at the "Blow" signal). The ten second sample was taken after the third complete respiration, the 15 second sample after the fifth, etc. It was later found that as rapid and complete a mixture of rebreathed gases could apparently be obtained by respiring only once in 5 seconds, holding the air in the lungs for about 2 seconds following each inspiration. At the end of the expiration when the last sample was taken, valve $\mathbf{E}$ was turned again, thus shutting off the air in the bag, and the experiment was ended.

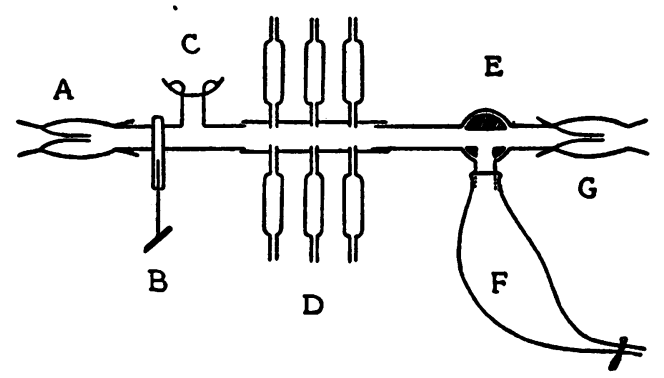

\section{Fig. 2. Diagram of Apparatus Used for Oxygenated Mixed Venous Tension Determinations}

$A$, intake flutter valve; $B$, shut-off slide valve; $C$, mouthpiece; $D$, six evacuated gas sampling tubes; $E$, three-way valve; $F$, rebreathing bag, containing $\mathrm{CO}_{2}-\mathrm{O}_{2}$ mixture; $G$, outgo flutter valve.

A sample of the bag air was taken, immediately, to compare with that in the last evacuated sampling tube.

Usually two such experiments were done in succession, the subject remaining at rest in the 10 to 15 minute interval between experiments. In some of the earlier experiments the subject did not remain at rest, but got up and moved about doing ordinary laboratory work.

(b) In the case of the experiments done with successive rebreathing periods the apparatus was the same, but the technique of collection differed slightly; at the end of a normal respiration, as before, the signal was given, the subject expired completely, slide valve $B$ was closed, and an alveolar sample taken. After three minutes rest, breathing through the apparatus, the same technique was repeated, except that after slide valve $B$ was closed, valve $\mathrm{E}$ was turned to connect bag and subject. The subject then rebreathed the gas mixture four times.in about 18 
seconds. At the end of the fourth expiration, one sample was taken into an evacuated tube, valve $E$ turned again to connect patient with outgo valve, and shut-off valve $B$ opened. The subject rested another 3 to 5 minutes (mouthpiece and noseclip still in place). Then another similar rebreathing was done, as described. This process was repeated every 3 to 5 minutes for five to six periods.

Following this experiment, after a further 10 to 15 minute rest, a single-period experiment (as in (a) above) was carried out, for comparison.

Samples were analyzed for $\mathrm{CO}_{2}$ with the Haldane apparatus.

The rebreathing bag contained 2.5 liters, the mixture consisting of oxygen plus varying amounts of $\mathrm{CO}_{2}$. In order to determine the limits for initial $\mathrm{CO}_{2}$ tension

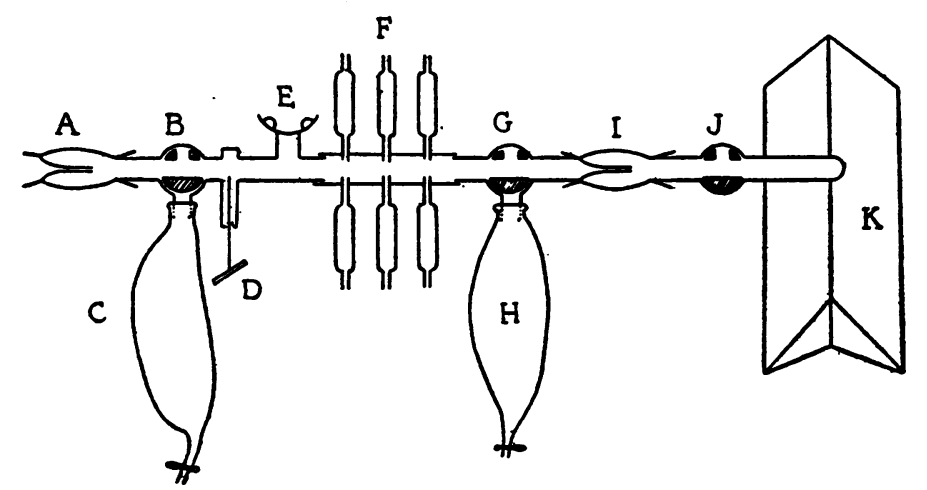

\section{Fig. 3. Diagram of Apparatus Used for True Mixed Venous Tension Determanations}

$A$, intake flutter valve; $B$, three-way valve; $C$, rebreathing bag, containing preliminary $\mathrm{CO}_{2}-\mathrm{N}_{2}$ mixture; $D$, shut-off slide valve; $E$, mouthpiece; $F$, six evacuated gas sampling tubes; $G$, three-way valve; $H$, rebreathing bag, containing $\mathrm{CO}_{2}-\mathrm{N}_{2}-\mathrm{O}_{2}$ mixture; $I$, outgo flutter valve; $J$, three-way valve; $K$, Douglas bag for collection of expired air.

in the bag, within which limits an apparent equilibrium could be obtained by rebreathing, widely different initial tensions were employed, varying from $45 \mathrm{~mm}$. to $80 \mathrm{~mm}$., as shown in tables 4 and 5 .

(c) For the determination of actual mixed venous tensions, a slightly modified apparatus was used, based on the technique described by Burwell and Robinson (20). A diagram of the apparatus is given in figure 3.

Bag C was filled with nitrogen plus a small amount-from $30 \mathrm{~mm}$. to $50 \mathrm{~mm}$.of $\mathrm{CO}_{2}$; this mixture was rebreathed twice, for the purpose of lowering the $\mathrm{O}_{2}$ tension in the residual air. Bag $\mathrm{H}$ was filled with a mixture containing about 55 $\mathrm{mm} . \mathrm{CO}_{2}, 35 \mathrm{~mm} . \mathrm{O}_{2}$, and the rest nitrogen. This latter mixture was worked out, partly by calculation and partly by trial and error, so as to make the resultant gas 
tensions, after mixture by rebreathing, as nearly as possible the same as those of the incoming venous blood; i.e., so as to reduce the necessary equilibration to a minimum.

The technique of these experiments, in further detail, was as follows: After the preliminary rest period, and the five to ten minutes of breathing through the apparatus, the signal "Blow" was given, as before, at the end of a normal expiration, and a complete expiration made. Valve $B$ was then opened from bag $\mathbf{C}$ to the subject, and valve $\mathrm{J}$ closed off. Two complete respirations were made into bag C. Slide valve $D$ was then closed and valve $G$ opened between bag $H$ and the subject. Complete respirations were then made every 5 seconds, a sample being taken into one of the sampling tubes at the end of each, and the exact second of taking noted. The stopwatch was started at the signal "Blow." When the last sample was taken, at the end of about thirty seconds, valve $G$ was closed to the bag and the experiment ended.

The subject was usually moderately cyanosed and dyspneic following these experiments.

After a fifteen to twenty minute rest period, a set of oxygenated mixed venous tensions was obtained as described under $(a)$ above. On one occasion the order was reversed, the oxygenated experiment being done first. No difference was noted.

In certain experiments, for the purpose of obtaining the respiratory quotient, a 5 or 6 minute volume of expired air was collected in a Douglas bag, before the rebreathing was begun, and analyzed for $\mathrm{O}_{2}$ and $\mathrm{CO}_{2}$. A sample of room air was usually also analyzed, as the intake valve did not lead in from the outside air.

\section{RESULTS}

\section{(a) Oxygenated mixed venous blood tensions}

In tables 4 and 5 are given the results, according to the technique described above, of forty-six consecutive experiments with subject D. W. R., and of ten experiments with subject M. L. S. In the case of the former subject this represents every experiment that was done except for two preliminary ones with a slightly different technique. In the case of M.L. S., one day's experiments were discarded because of leaks discovered in the sampling tubes. Every $\mathrm{CO}_{2}$ determination that was made is also given, but certain values which are enclosed in brackets, are not included in the further calculations, as being improbably far from other values.

In the tables, it will be noted that the second column gives the $\mathrm{CO}_{2}$ tensions in the bag before rebreathing was begun, and the next column the $\mathrm{CO}_{2}$ tension of the alveolar air. The fourth, sixth, etc. columns 
give the $\mathrm{CO}_{2}$ tensions in the fifth-, tenth-, fifteenth-, etc., second samples, and the intervening columns (fifth, seventh, etc.) give the $\mathrm{CO}_{2}$ tension differences between these successive 5-second values. The figures in parentheses are the $\mathrm{CO}_{2}$ tensions of samples taken from the rebreathing bag after the procedure was ended; these in general are close to the values of the last of the samples taken in the evacuated sampling tubes.

The experiments are listed in five groups, according to the initial $\mathrm{CO}_{2}$ tensions in the rebreathing bag; Group I, 50 to $56 \mathrm{~mm}$.; Group II, 56 to $60 \mathrm{~mm}$.; Group III, 60 to $65 \mathrm{~mm}$.; Group IV, 65 to $70 \mathrm{~mm}$.; Group V, 70 to $80 \mathrm{~mm}$. The separation of Groups I and II at $56 \mathrm{~mm}$. is made because of the well defined difference that occurs in the series below this value as compared with the series above.

Averages of all figures are given at the end of each group.

In figure 4, these averages for subject D. W. R. are presented in graphic form. It will be noted that there is in this figure an ordinate marked "Estimated mixed $\mathrm{CO}_{2}$ tension." This is an estimate of the concentration of $\mathrm{CO}_{2}$ in the mixed respired gases, calculated from the volume of bag air, its $\mathrm{CO}_{2}$ content, the volume of residual air, ${ }^{1}$ and its $\mathrm{CO}_{2}$ content. It is assumed that no absorption or elimination of gases by the blood has taken place. The resultant figure gives an approximate measure of the extent of change required for the establishment of equilibrium between lungs and incoming venous blood.

Considering for the moment only the experiments on D. W. R., one finds certain points brought out:

1. In the group where the initial bag tensions were 50 to $56 \mathrm{~mm}$. it is clear that no consistent "plateau" level is reached at any time. There is thus no evidence that an equilibrium has been achieved between lung gases and incoming venous blood. There are considerable differences of tension between successive sets of samples taken at

\footnotetext{
${ }^{1}$ The subject's residual air was calculated by having him expire completely, then rebreathe from a spirometer a high $\mathrm{O}_{\varepsilon}$ mixture several times in 15 seconds, (to obtain complete mixing), then again expire completely into the spirometer. The nitrogen in residual air was assumed to be 75 per cent of the total gas volume (25 per cent taken by $\mathrm{CO}_{2}, \mathrm{O}_{2}$, and water vapor). From this value, the volume of the gases in the spirometer at the end of rebreathing, and the percentages of $\mathrm{N}_{2}$ in the spirometer at the beginning and end of rebreathing, the approximate value of the residual air can readily be calculated. For subject D. W. R. this volume was about $2000 \mathrm{cc}$.
} 
5 second intervals. (On the chart there is an apparent equilibrium from 10 to 15 seconds, but reference to the table will show that this is false, and due to the fact that for certain experiments no 10 -second sample was obtained.)

2. In the next three groups, with initial tensions at 56 to $60 \mathrm{~mm}$., 60 to $65 \mathrm{~mm}$., and 65 to $70 \mathrm{~mm}$., there is a clear cut "plateau" found

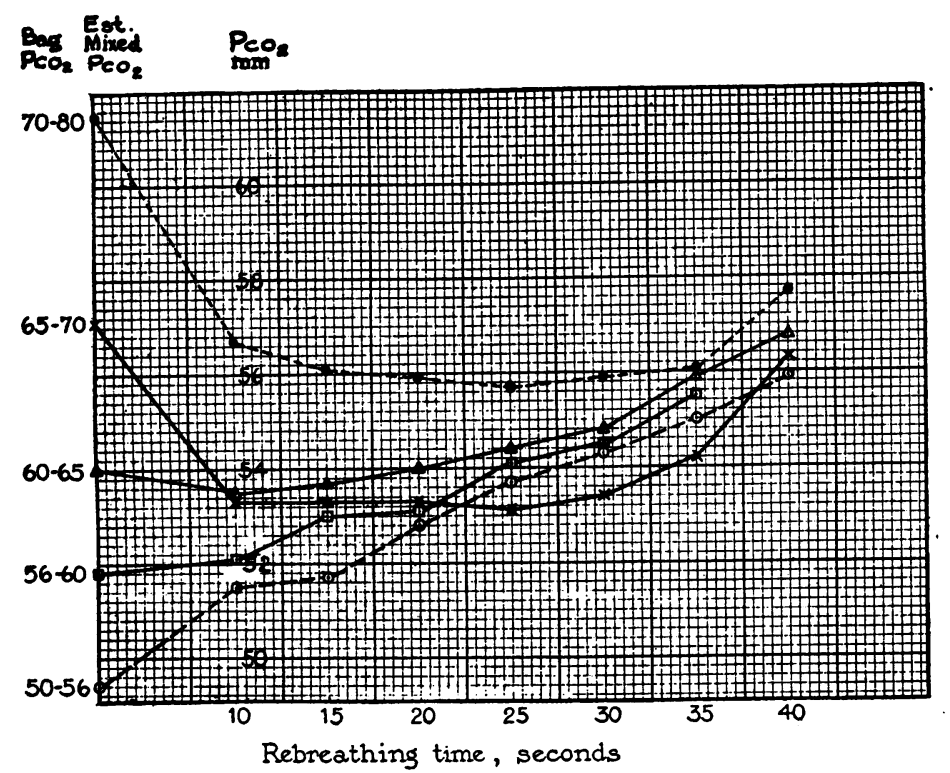

Fig. 4. Oxygenated Mixed Venous $\mathrm{CO}_{\varepsilon}$ Tensions

Ordinates, tensions of $\mathrm{CO}_{2}, \mathrm{~mm}$. $\left(=\mathrm{P}_{\mathrm{CO}_{2}}\right)$. Abscissae, time at which sample was taken, expressed as the number of seconds after rebreathing was begun. The "Bag $\mathrm{P}_{\mathrm{CO}_{2}}$ " figures indicate the initial tensions in the rebreathing bag, for the particular group of experiments represented by the adjacent line and symbol. For explanation of "Estimated $\mathrm{P}_{\mathrm{CO}_{2}}$ " tensions, see text. Each line represents the average $\mathrm{CO}_{\varepsilon}$ tension change during rebreathing, for that group of experiments.

between the fifteenth and twentieth second. This is demonstrated not only in the average figures, but in almost every one of the individual experiments: thus, of the twenty-seven experiments, there were two differences of $+0.8 \mathrm{~mm}$. $\mathrm{CO}_{2}$ in the 15 to 20 second interval, one of $+0.6 \mathrm{~mm}$., and one of $+0.4 \mathrm{~mm}$., all the rest being between 
$\pm 0.3 \mathrm{~mm}$. As the error of method in the Haldane gas analyses is itself about $0.2 \mathrm{~mm}$., this degree of variation can be considered small. Thus there is found at the plateau level both a decrease in the amount of average change in level over the interval, as compared with earlier and later intervals, and a decrease in the deviations of individual values from the average, when compared with similar deviations for the differences in other time intervals.

Even over this plateau, however, it is clear that there is a small rise in $\mathrm{CO}_{2}$ tension in most instances, with an average change of +0.19 $\mathrm{mm} . \mathrm{CO}_{2}$. This may be due to the recirculation of increasing small amounts of blood, or it may be in part, at least, an effect due to oxygen absorption, discussed in the previous part. In either case, the plateau level should then be slightly above the actual oxygenated mixed venous level.

3. Beginning at 25 seconds, there is a progressive rise in $\mathrm{CO}_{2}$ level, presumably due to increasing amounts of recirculating blood.

4. The average $\mathrm{CO}_{2}$ tension level in the three groups is nearly the same, being (at the fifteenth second) $53.0 \mathrm{~mm}$. for Group II, $53.7 \mathrm{~mm}$. for Group III, and $53.3 \mathrm{~mm}$. for Group IV. The fact that with these considerable variations in initial bag mixture, the plateau level is nearly the same is further evidence that this plateau represents a true equilibrium condition.

5. Although average plateau levels are nearly the same, individual experiments show considerable variations in this respect. The lowest figure at 15 seconds is $52.6 \mathrm{~mm}$., and the highest $55.9 \mathrm{~mm}$. Such variations are to be expected. The work of Higgins (29) and later of Dodds (30) on alveolar air values, during the course of the day, and that of Cullen and Earle (31) more recently, on the arterial $\mathrm{pH}_{\mathrm{s}}$ and $\mathrm{CO}_{2}$ tensions, show that considerable variations take place, and it is reasonable to suppose similar changes in mixed venous levels. There are, in fact, some early experiments by Porges, Leimdörfer, and Markovici (32), using the original Plesch method, which showed such variations in mixed venous tensions. It is clear, for instance, from our data, that the mixed venous tension level is usually higher in the afternoons than in the late mornings. A further point, which is obvious enough but easy to lose sight of, is that these data represent 
tensions only. A change in level of $\mathrm{CO}_{2}$ curve would change the $\mathrm{CO}_{2}$ tension also, providing $\mathrm{pH}_{\mathrm{s}}$ values were constant.

6. When one considers the equilibrium levels in any two experiments done on the same morning or afternoon, the variations are smaller. There are five such groups, done on December 10, 14, 19, 21, and 31. In the cases of the first two of these, the subject was not at rest between experiments but got up and performed ordinary laboratory activity. The equilibrium (15 second) levels were $53.6 \mathrm{~mm}$. and $52.9 \mathrm{~mm}$. on December 10, and $52.8 \mathrm{~mm}$. and $54.3 \mathrm{~mm}$. on December 14 . In the remaining three groups the subject remained at rest between experiments. The equilibrium levels were: $53.4 \mathrm{~mm}$. and $52.6 \mathrm{~mm}$. on December 19, $52.8 \mathrm{~mm}$. and $53.4 \mathrm{~mm}$. on December 21, and $54.8 \mathrm{~mm}$. and $54.1 \mathrm{~mm}$. on December 31. Thus it can be said that by this technique the apparent equilibrium values for successive experiments done within an hour, and with the subject at rest, differ by less than $1 \mathrm{~mm}$.

7. Reference to the "Estimated mixed $\mathrm{CO}_{2}$ tension" points in figure 4 will show that the equilibrium obtainable in the three groups II, III and IV corresponds in general with the fact that there is relatively little change necessary in the lung gases, after mixture, during the equilibration process. This is not so true of the 65 to $70 \mathrm{~mm}$. group (IV) as the others, there being an excess of $\mathrm{CO}_{2}$ in the lung air in these experiments. It is probable that lung tissue fluids are able to absorb appreciable amounts of this excess, in their change from alveolar to mixed venous tensions.

8. In the group in which the initial tensions in the bag were $70 \mathrm{~mm}$. or over, there are also excellent plateaux formed, even flatter than in the preceding three groups, but their levels are definitely higher than the latter. Evidently the blood is unable to absorb all the excess of $\mathrm{CO}_{2}$ in the lung-bag air before recirculation begins. It is to be noted that the plateau level rises only gradually above that of the lower groups, when the initial bag tension is increased from 70 to $80 \mathrm{~mm}$. This has been explained in the theoretical discussion preceding.

9. There seems to be also a tendency for the $\mathrm{CO}_{2}$ tension to rise less rapidly in the period from 25 to 35 seconds, when the initial $\mathrm{CO}_{2}$ tensions in the rebreathing bag are high (see fig. 4). If this is true, it is difficult to explain: one would expect the opposite. Is it possible 
that the arterial blood highly charged with $\mathrm{CO}_{2}$ can dilate the tissue capillaries and venules to such an extent as to delay appreciably the recirculation of this particular part of the total blood volume? It is certainly true that the rebreathing of these higher $\mathrm{CO}_{2}$ mixtures is associated with definite flushing of the skin and sensation of warmth.

The ten experiments performed on subject M. L. S., listed in table 5 , give generally similar results to those just described. The $\mathrm{CO}_{2}$ tension level in this subject was considerably lower than in the other, an average of $38.2 \mathrm{~mm}$. for alveolar air, and of $46.7 \mathrm{~mm}$. for mixed venous level. In the experiments in which the initial $\mathrm{CO}_{2}$ tensions in the bag were $45 \mathrm{~mm}$. and $48 \mathrm{~mm}$., these values were too low for the establishment of an equilibrium level. In the six experiments in which the initial concentration in the bag was near $50 \mathrm{~mm}$., it will be noted that the equilibrium level was in three cases attained in the 15 to 20 second interval, and in two cases in the 10 to 15 second interval. In one case the 15 second point was slightly below either of the two adjacent points. Apparently in this subject, recirculation of blood may take place in appreciable amounts in less than twenty seconds; the experiments are too few to decide this point. The two experiments with initial tensions of $60 \mathrm{~mm}$. give plateau values definitely higher than the $50 \mathrm{~mm}$. group. Probably this initial tension is beyond the equilibrating limit for this subject. This tension $(60 \mathrm{~mm}$.) is about $13 \mathrm{~mm}$. higher than the apparent oxygenated mixed venous level; subject D. W. R. reached equilibrium with initial rebreathing mixtures up to $17 \mathrm{~mm}$. above this level. This may have been due to the larger lung volume and residual air in the latter subject.

The definite equilibrium levels demonstrated above have, of course, been found by most workers on this subject in the past. The method which we have used, in establishing the limits of composition of rebreathed air, with which this equilibrium can be obtained, adds, we believe, further evidence in confirmation of their results.

(b) Oxygenated mixed venous tensions, method of successive rebreathings

Three experiments by this method were performed with subject D. W. R., according to the technique described above, each of these experiments being followed, after a fifteen minute interval, by another experiment of the series just described (single rebreathing 
period), for comparison. In two of these, the breath was held for 18 seconds each time, in the third (as described under Methods) the mixture was rebreathed slowly four times in the 18 seconds. This difference of technique made no significant difference in results.

A comparison of the results by the two methods is given in table 6 . It will be seen that the apparent "mixed venous" level by the successive rebreathing method was considerably lower than by the other method, in all three experiments; the level in the former group being $2 \mathrm{~mm}$. or more lower than that in any of the 46 experiments by the other method. The slight lowering of $\mathrm{CO}_{2}$ values after the fourth successive rebreathing period was due presumably to a lowering of $\mathrm{O}_{2}$ tension, the venous blood not becoming completely oxygenated. In

TABLE 6

Oxygenated mixed venous $\mathrm{CO}_{2}$ tensions by different methods

\begin{tabular}{|c|c|c|c|c|c|c|c|c|c|c|c|c|}
\hline \multirow{4}{*}{ Date } & \multicolumn{6}{|c|}{ A. Single rebreathing period } & \multicolumn{6}{|c|}{ B. Successive rebreathings } \\
\hline & \multirow{3}{*}{$\begin{array}{c}\text { Initial } \\
\text { bag } \\
\mathrm{CO}_{2} \\
\text { tension }\end{array}$} & \multicolumn{5}{|c|}{$\begin{array}{l}\text { Seconds after beginning } \\
\text { rebreathing }\end{array}$} & \multirow{3}{*}{$\begin{array}{c}\text { Initial } \\
\text { bag } \\
\mathrm{CO}_{\mathbf{i}} \\
\text { tension }\end{array}$} & \multicolumn{5}{|c|}{ Rebreathing period } \\
\hline & & 10 & 15 & 20 & 25 & 30 & & 1st & 2nd & 3 rd & 4th & 5th \\
\hline & & \multicolumn{5}{|c|}{$\mathrm{CO}_{2}$ tension } & & \multicolumn{5}{|c|}{$\mathrm{CO}_{2}$ tensions } \\
\hline & $m m$. & $m m$. & mm. & mm. & mm. & $m m$. & $m m$. & $m m$. & $m m . \mid$ & $m m$. & $m m$. & $m m$. \\
\hline January $28 . .$. & 61.2 & 53.6 & 53.8 & 54.6 & 54.6 & 55.5 & 50.6 & 50.6 & 49.9 & 50.9 & 50.1 & 49.6 \\
\hline February $1 \ldots$ & 60.2 & 52.6 & 52.4 & 52.7 & 53.6 & 54.0 & 64.7 & 51.9 & 49.4 & 49.4 & 49.3 & 49.2 \\
\hline February $4 . . .$. & 57.0 & 51.2 & 52.2 & 52.5 & 53.1 & 53.6 & 58.7 & 52.0 & 50.7 & 50.3 & 50.3 & 49.7 \\
\hline
\end{tabular}

the experiment of February 1, the $\mathrm{O}_{2}$ tension in the fourth sample was $110.0 \mathrm{~mm}$., in the fifth sample $89.6 \mathrm{~mm}$.

It is concluded that for this subject, the method of successive rebreathing from the same bag without enriching the mixture with $\mathrm{CO}_{2}$, gives equilibrium values below those obtained by the single rebreathing method.

One similar experiment with subject M. L. S. seemed to show the same thing, but these data were not enough to decide the point.

(c) True mixed venous blood tensions

In order that a comparison may be made between mixed venous $\mathrm{CO}_{2}$ content of blood as derived from oxygenated tension methods, and mixed venous $\mathrm{CO}_{2}$ content of blood as derived by true tension methods 
(equilibrating both $\mathrm{CO}_{2}$ and $\mathrm{O}_{2}$ simultaneously), the $\mathrm{CO}_{2}-\mathrm{O}_{2}$ relationships must be known. For blood itself, these relations can, of course, be demonstrated by constructing a nomogram. If lungs and pulmonary vein blood are in approximate equilibrium at every moment during the rebreathing procedure, then the course of equilibration, as shown by successive $\mathrm{CO}_{2}$ and $\mathrm{O}_{2}$ tensions, can be plotted on this nomogram. A comparison can then be made between $\mathrm{CO}_{2}$ content as obtained by the true and by the oxygenated method.

Making provisionally this assumption of approximate lung-blood equilibrium, we constructed a $\mathrm{CO}_{2}-\mathrm{O}_{2}$ nomogram of the blood of D. W. R., and a similar but less complete nomogram of the blood of M. L. S.

TABLE 7

$\mathrm{CO}_{2}$ dissociation curves of reduced and oxygenated blood. Subject $D . W . R$.

\begin{tabular}{c|c|c|c|c}
\hline \multicolumn{2}{c|}{ Oxygenated } & \multicolumn{3}{c}{ Reduced } \\
\cline { 5 - 5 } Total $\mathrm{CO}_{2}$ & $\mathrm{CO}_{2}$ tension & Total $\mathrm{CO}_{2}$ & $\mathrm{CO}_{2}$ tensions & Total $\mathrm{O}_{2}$ \\
\cline { 5 - 5 } volumes per cent & mm. & volumes per cent & mm. & volumes per cent \\
43.5 & 31.1 & 46.4 & 26.2 & 1.9 \\
43.7 & 31.2 & 60.4 & 52.1 & 1.7 \\
53.3 & 48.5 & 64.2 & 54.4 & 0.9 \\
60.9 & 65.6 & & & \\
\hline
\end{tabular}

To describe first the nomogram of subject D. W. R.:- $\mathrm{CO}_{2}$ curves of reduced and of oxygenated blood were made. The technique of blood-gas analysis which we used has been described in a previous paper (33); in general it follows the method developed by Austin, Van Slyke, et al. (34). The Van Slyke-Neill (35) manometric apparatus, and the Boothby modification of the Haldane gas analysis apparatus were used for blood and gas analyses respectively. The blood was prevented from clotting by the use of small amounts of heparin, and dry $\mathrm{NaF}$ was added, to give a final concentration of about 0.1 per cent, as a preservative. It was thought at first that this would prevent the loss of $\mathrm{CO}_{2}$ capacity during equilibration in the tonometers. Following a suggestion kindly made by Dr. J. H. Talbott, however, we investigated this assumption, and found it incorrect, the blood losing about $0.6 \mathrm{cc}$. of $\mathrm{CO}_{2}$ per $100 \mathrm{cc}$. blood, per hour of equilibration at $37.5^{\circ} \mathrm{C}$. We, therefore, corrected our $\mathrm{CO}_{2}$ content figures accordingly. Three 
points were determined on the reduced and four on the oxygenated $\mathrm{CO}_{2}$ curves, and the curves drawn by the use of the straight line logarithmic relation of Peters, Eisenman, and Bulger (36). The data for the curves are given in table 7 .

The tonometers employed for the reduced $\mathrm{CO}_{2}$ curve determinations actually contained small amounts of $\mathrm{O}_{2}$. This was measured in both blood and gas phases, and a correction readily obtained by plotting the actual points on a $\mathrm{CO}_{2}-\mathrm{O}_{2}$ diagram, and with the aid of the oxygenated $\mathrm{CO}_{2}$ curve, extrapolating to the line of zero oxygen content. By

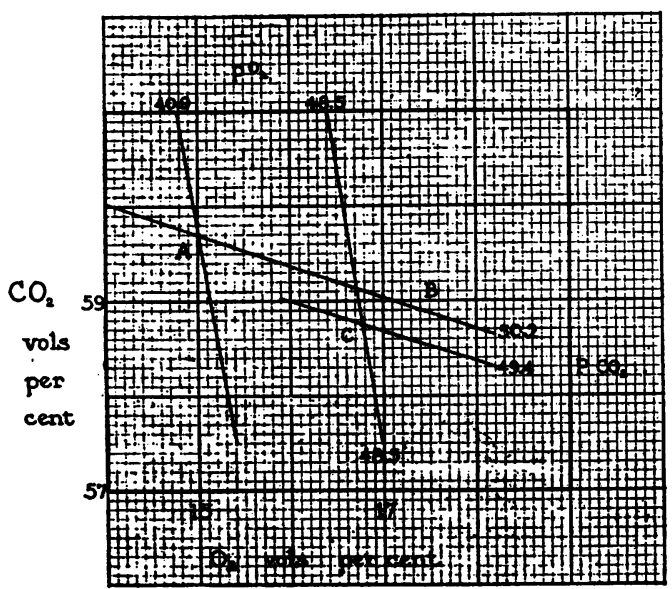

Fig. 5. EXPermuent of May 13, 1929

Chart represents part of a $\mathrm{CO}_{2}-\mathrm{O}_{2}$ nomogram of the blood of subject D. W. R. Point $B=$ arterial blood at the end of 20 seconds rebreathing of mixed venous gas mixture. Point $C=$ gas tensions in the lungs after 20 seconds' rebreathing.

the use of these extrapolated points, a completely reduced $\mathrm{CO}_{2}$ curve was obtained.

In a previous study (33), complete oxygen dissociation curves on subject D. W. R. had been determined; these were used for the nomogram. Various workers have found that the $\mathrm{O}_{2}$ dissociation curves of one individual change little from one year to the next $(13,37)$. One point was, however, determined again at an oxygen tension of $40 \mathrm{~mm}$., and $\mathrm{CO}_{2}$ tension of $50 \mathrm{~mm}$.; this point, when plotted on the $\mathrm{O}_{2}$ dissociation curve chart constructed three years previously, fell within 0.3 
volumes per cent (of $\mathrm{O}_{2}$ ) of its proper place; this is within the experimental error of the technique employed.

It may also be noted that the $\mathrm{CO}_{2}$ curves which were made had prac-

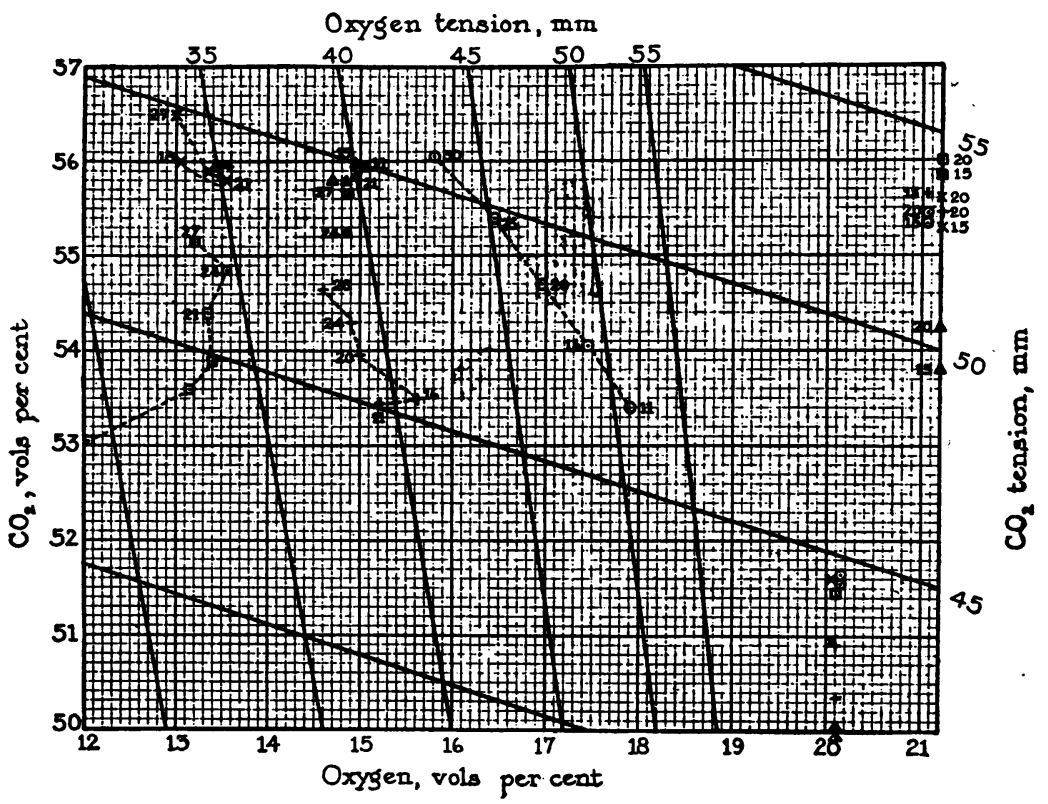

Fig. 6. $\mathrm{CO}_{2}-\mathrm{O}_{2}$ Nomogram of Blood of Subject D. W. $\mathbf{R}$.

Plotted on it are the progressive changes, during the course of rebreathing, in $\mathrm{CO}_{2}$ and $\mathrm{O}_{2}$ tensions in lung-bag air, of five experiments. The figure beside each point represents the number of seconds after beginning rebreathing, at which that particular sample was taken. At the right of the diagram, along the completely oxygenated line, are the equilibrium (15 to 20 second) tensions of a corresponding series of oxygenated mixed venous experiments. Alveolar air tensions are plotted along the 95 per cent oxygen saturation (arterial) line. Each symbol represents one day's experiments, as follows: squares, February 13; crosses, February 16; triangles, February 18; plus marks, March 7; circles, March 11.

tically the same levels as had the $\mathrm{CO}_{2}$ curves of this subject at the time the $\mathrm{O}_{2}$ dissociation curves were studied.

The nomograms of the blood are used in figures 6,7 , and 8 .

Before considering the rebreathing experiments, it is important to give the evidence which we have for the assumption of lung-blood 
equilibrium during rebreathing. This experiment was performed on May 13, as follows:

The subject, after a half hour rest, applied mouthpiece and nose-clip and breathed through the apparatus (fig. 3). The two rebreathing bags had been filled with the following mixtures: Bag C, with 275 cc. $\mathrm{CO}_{2}$ and 2,225 cc. $\mathrm{N}_{2} ; \mathrm{Bag} \mathrm{H}$ with $225 \mathrm{cc}$. $\mathrm{CO}_{2}, 650 \mathrm{cc}$. of air, and 1,625

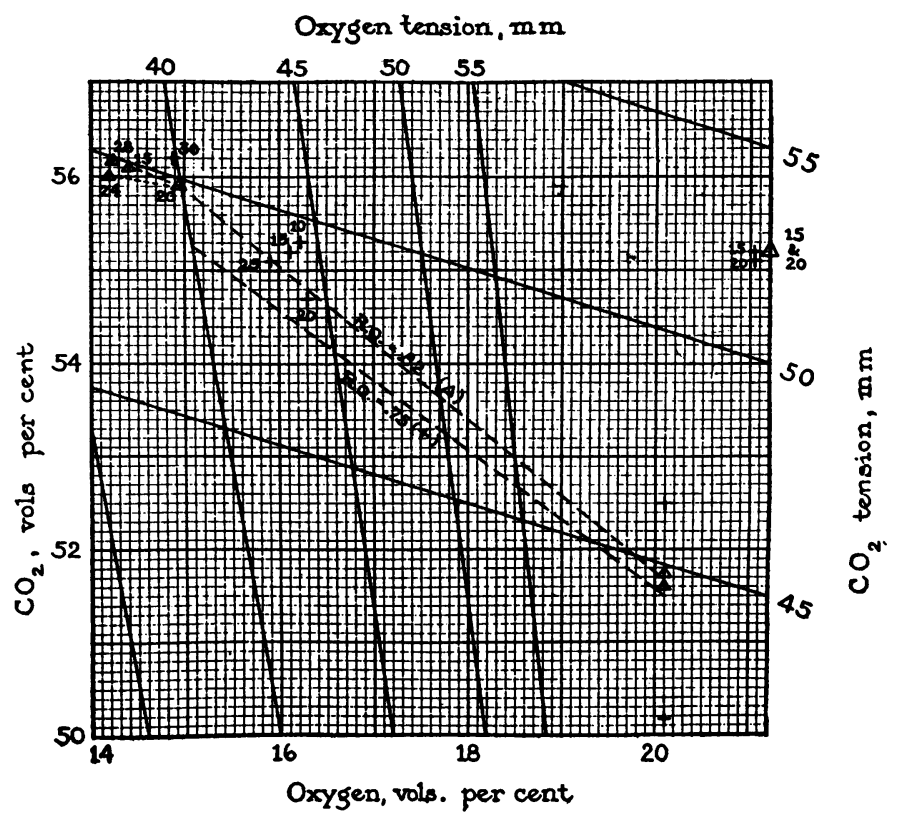

Fig. 7. $\mathrm{CO}_{2}-\mathrm{O}_{2}$ Nomogram of Blood of Subject D. W. R.

For explanation see figure 6, and text. Triangles = experiments of March 15. Plus marks = experiments of March 20.

cc. $\mathrm{N}_{2}$. Just before the rebreathing procedure was begun, an arterial puncture was made into the brachial artery, but no blood drawn. The rebreathing was then performed, as described above. At the twentieth second of rebreathing, a signal was given and the assistant at the artery began drawing blood (under oil) and continued for the following twelve seconds. Rebreathing was continued by the subject during this interval, and the usual gas samples.taken.

The blood was transferred under oil to a tube containing a small 
amount of anticoagulant, dried neutral potassium oxalate being used in this instance (final concentration about 0.2 per cent), plus enough dried $\mathrm{NaF}$ to give a final concentration of 0.1 per cent. The arterial blood contents of $\mathrm{CO}_{2}$ and $\mathrm{O}_{2}$ were measured at once, and the remainder of the blood transferred to a tonometer containing about $50 \mathrm{~mm}$. $\mathrm{CO}_{2}$ and $40 \mathrm{~mm} . \mathrm{O}_{2}$. This blood was equilibrated at $37.5^{\circ} \mathrm{C}$. for 50 minutes, and $\mathrm{CO}_{2}$ and $\mathrm{O}_{2}$ then determined on both blood and gas

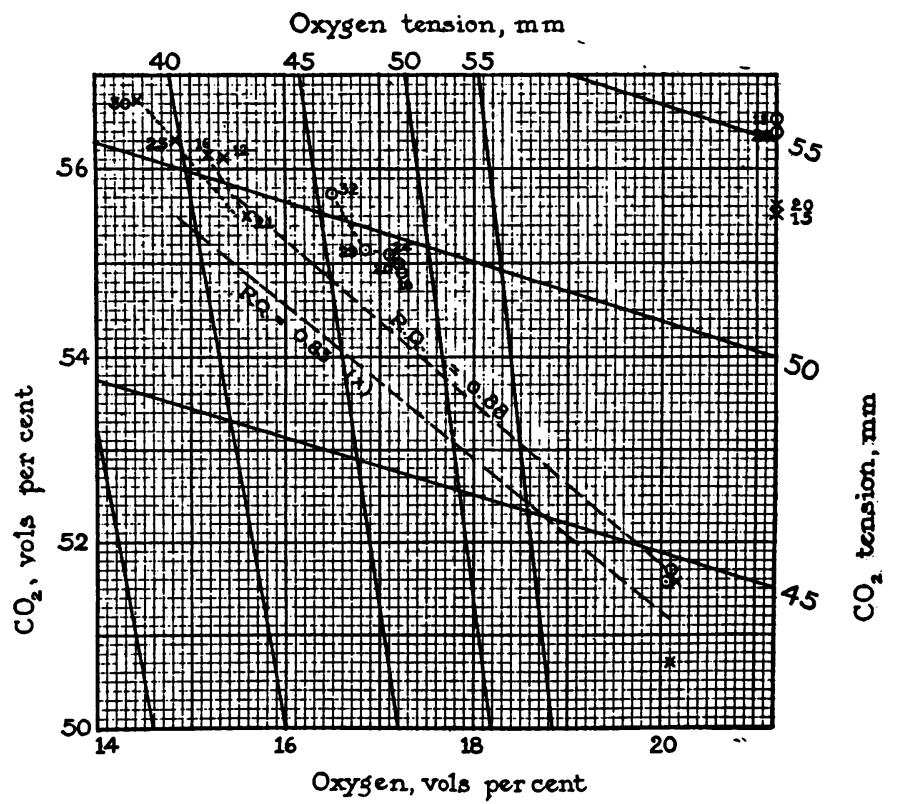

Fig. 8. $\mathrm{CO}_{2}-\mathrm{O}_{2}$ Nomogram of Blood of Subject D. W. $R$.

For explanation see figure 6 , and text. Crosses = experiments of May 3 . Circles = experiments of May 13.

phases. After correction had been made for $\mathrm{CO}_{2}$ capacity lost during equilibration, the final figures were as shown in table 8. The tensions in the lung air during rebreathing were as shown in table 9.

It is evident that from the sixteenth to the twenty-fourth second, a nearly perfect equilibrium was apparently maintained in the lung gases. Inasmuch as it probably takes several seconds for the blood to go from lung alveoli to brachial artery, the arterial blood drawn from 
the twentieth to the thirty-second second must have come near being the blood which passed through the lung alveoli during the interval of equilibrium.

If equilibrium were perfect between lungs and blood, and technique of blood handling, etc., were faultless, then the arterial blood gas contents, and the lung tensions, when plotted on a $\mathrm{CO}_{2}-\mathrm{O}_{2}$ nomogram, should fall on the same point. Such a nomogram is given in figure 5, point $A$ being that of the blood and gases in the tonometer, and the tension lines of this diagram drawn with distances and slopes

TABLE 8

Evidence of lung-blood equilibrium during rebreathing

\begin{tabular}{|c|c|c|c|c|c|}
\hline \multicolumn{2}{|c|}{ Arterial blood contents } & \multicolumn{4}{|c|}{ Blood equilibrated at $37.5^{\circ} \mathrm{C}$. } \\
\hline $\mathrm{CO}_{2}$ & $\mathrm{O}_{2}$ & \multicolumn{2}{|c|}{$\mathrm{CO}_{2}$} & \multicolumn{2}{|c|}{$\mathrm{O}_{2}$} \\
\hline volumes per cent & volumes per cent & oolumes per cent & mm. & volumes per cent & $m m$. \\
\hline 59.0 & 17.4 & 59.7 & 50.2 & 15.0 & 40.9 \\
\hline
\end{tabular}

TABLE 9

Tensions in lung air, same experiment as table 8

\begin{tabular}{c|c|l}
\hline Time after starting & $\mathrm{CO}_{2}$ & $\mathrm{O}_{2}$ \\
\hline seconds & mm. & mm. \\
16 & 49.3 & 48.7 \\
20 & 49.4 & 48.5 \\
24 & 49.5 & 48.1 \\
29 & 49.6 & 47.0 \\
32 & 50.5 & 45.5 \\
\hline
\end{tabular}

corresponding to those of the more complete nomogram of this subject's blood, previously described. This is probably a justifiable extrapolation, over so small an area of the nomogram. Point $B$ is the "mixed venous" blood (as drawn from brachial artery), and $C$ the lung tensions after 20 seconds' rebreathing. It will be seen that the differences between the two points $(B$ and $C)$ are small: 0.25 volumes per cent, or $0.8 \mathrm{~mm}$. of $\mathrm{CO}_{2}$, and 0.6 volumes per cent, or about $3 \mathrm{~mm}$. of $\mathrm{O}_{2}$. Considering the amount of manipulation of blood necessary, this agreement is fairly good. The chief discrepancy is in oxygen, the arterial blood value being too high. The slow diffusion rate of 
oxygen as compared with that of $\mathrm{CO}_{2}$ is probably an important factor in delaying this equilibrium.

We ought to have done more experiments of this sort. It was not easy, however, to time the procedure accurately, and several unsuccessful attempts were made.

It may be concluded from this experiment that when the lung gases are at equilibrium during rebreathing (in the region of mixed venous levels), there is also approximate equilibrium between these gases and the blood leaving the pulmonary capillaries.

One cannot, of course, conclude that there is equilibrium at any moment between lungs and pulmonary vein blood, when the pulmonary artery blood varies considerably from lung tensions. However, for small lung-blood differences the discrepancy will be relatively small. One can be justified, therefore, in using blood nomograms to represent the course of equilibration during lung-blood experiments. Their direction of change will be properly represented, and if an apparent equilibrium level is reached (as indicated by constant lung tensions) then it will be known that lungs and blood have nearly the same tensions.

In the case of oxygenated mixed venous tension experiments, the demonstration of equilibrium between lungs and blood after 15 seconds' rebreathing was made, as noted above, by Field, Bock, et al. (16).

Figures 6, 7, and 8 are $\mathrm{CO}_{2}-\mathrm{O}_{2}$ nomograms of the blood of D.W. R. on which are plotted the $\mathrm{CO}_{2}$ and $\mathrm{O}_{2}$ tensions of samples of rebreathed mixtures taken at successive intervals after the beginning of rebreathing using the technique described under Method $(c)$. Each experiment is represented by a series of four to six points, connected by a dotted line, the number beside each point indicating the number of seconds after starting rebreathing, at which the sample was taken. At the extreme right, along the line of complete oxygen saturation are given, for purposes of comparison, the levels, in $\mathrm{CO}_{2}$ tensions, of the fifteenth and twentieth second samples of the oxygenated mixed venous tension experiments. As stated above, one of these was done, in every instance, after the true mixed venous tension experiment had been completed. There may be a small error involved here, as the blood hemoglobin even with the rebreathing of high oxygen mixtures, may not become completely saturated (see Part I). Along the 9.5 per cent 
saturation line are plotted the $\mathrm{CO}_{2}$ tensions of alveolar air samples (corresponding to arterial blood $\mathrm{CO}_{2}$ tensions).

It is clear that if both methods ("true" and "oxygenated") actually give at equilibrium the tensions of the incoming blood, and the latter remain unchanged during the procedures, then both equilibrium points on the nomogram will lie on the same $\mathrm{CO}_{2}$ content line.

Each pair of experiments done on the same day (one "true" and one "oxygenated") are presented on the figures by one symbol (triangle, cross, etc.).

Perfect equilibrium on the nomogram is, of course, represented by the exact superposition of two or more successive samples.

On figure 6 are given the results of five experiments, in four of which, so far as the true mixed venous tensions were concerned, equilibrium was evidently not arrived at.

In the experiment of February 13, for example, the initial mixture in the rebreathing bag was too low both in $\mathrm{CO}_{2}$ and $\mathrm{O}_{2}$. The $\mathrm{CO}_{2}$ progressively increased during rebreathing, and the $\mathrm{O}_{2}$ at first increased and then, after the twenty-fourth second, diminished, indicating recirculating blood. The oxygenated tension experiment reached a plateau value at $54.0 \mathrm{~mm}$., as shown. This corresponds to 55.8 volumes per cent of $\mathrm{CO}_{2}$, well above any of the points on the other curve.

Similarly, the experiment of March 11 shows that the initial mixture was too high in $\mathrm{O}_{2}$ and too low in $\mathrm{CO}_{2}$. During rebreathing the $\mathrm{CO}_{2}$ tension progressively increased and $\mathrm{O}_{2}$ tension diminished. The plateau level of $\mathrm{CO}_{2}$ content in the oxygenated tension experiment was 55.4 volumes per cent. This value for $\mathrm{CO}_{2}$ was also reached in the "true" mixed venous experiment, but only after twenty-five seconds, a time when recirculation of blood had probably begun.

The experiment of March 7 is similar to that of March 11.

In the experiment of February 16, the three successive samples taken at 18,21, and 24 seconds have the same $\mathrm{CO}_{2}$ tensions and thus indicate an equilibrium with respect to this gas. Oxygen tensions showed an increase up to 21 seconds, followed by a decrease, suggestive evidence that the oxygen tension at 21 seconds was still below the equilibrium value. Further evidence in favor of this may be obtained by drawing an average R.Q. line (0.81) on the nomogram, starting from the alveolar air tension (as plotted on the 95 per cent $\mathrm{O}_{2}$ 
saturation line). This line will be found to fall well to the right of the 18,21 and 24 second points.

It will be noted that the 18 and 21 second $\mathrm{CO}_{2}$ levels were higher by about 0.4 volume per cent than the plateau values in the corresponding oxygenated tension experiment. This is probably due in part at least to the failure to equilibrate with respect to oxygen.

On February 18, apparently an equilibrium was reached and maintained several seconds, as shown by the close grouping of the points. Unfortunately it is not possible to compare the equilibrium value for the $\mathrm{CO}_{2}$ level with that of the corresponding oxygenated tension experiment, because the initial mixture used in the bag in the latter contained only $52.5 \mathrm{~mm}$. $\mathrm{CO}_{2}$, and a plateau level was, therefore, not reached in the fifteenth to the twentieth second. The level of the true mixed venous $\mathrm{CO}_{2}$ is, however, close to, though slightly above, the average level of equilibrium arrived at in other oxygenated tension experiments. There is a further difficulty with this experiment and that is the unusually low alveolar air tensions. These, when compared with the equilibrium point for the true mixed venous tension, give an impossibly high value for the R.Q. Where the error, or errors, occurred in this experiment we have been unable to discover.

In figures 7 and 8 are given four experiments in which a fairly close approach to equilibrium was achieved, as indicated both by the close grouping of the points, and their nearness to the R.Q. lines (slopes as determined by analyses of expired air, lines drawn from alveolar air points on figure). It will be seen that the points are clustered around the same $\mathrm{CO}_{2}$ content lines as are the corresponding equilibrium values for the oxygenated tension experiments (plotted at the right of the nomogram). On May 13, the initial tension in the bag for the oxygenated tension experiment was over $70 \mathrm{~mm}$., so that the tension at the "plateau" level, $55.3 \mathrm{~mm}$., was almost certainly too high. Disregarding this experiment, the differences in $\mathrm{CO}_{2}$ content level between the true and the oxygenated equilibrium values (average of fifteenth and twentieth second samples) were as follows: March $15,+0.7$ volumes per cent (i.e., "true" higher than "oxygenated"); March 20, -0.2 volumes per cent; May 3, +0.3 volumes per cent, an average of +0.3 volumes per cent.

There seems to be a tendency for the true equilibrium values to 
fall somewhat to the right of their respective R.Q. lines. The reason for this is not clear.

It will be noted in these true mixed venous experiments, that equilibrium is much more readily obtained with respect to $\mathrm{CO}_{2}$ than $\mathrm{O}_{2}$. This is to be expected, and has been considered in the theoretical discussion preceding. Both the small amounts of oxygen available from the blood, and the slow diffusion rate of this gas, will delay equilibrium.

We may note also that the nine experiments above described are all that were done with this technique on this subject.

We had hoped to find some evidence as to whether the concentrating effect of oxygen absorption (see Part I) would make the equilibrium $\mathrm{CO}_{2}$ content levels of the oxygenated tension experiments higher than those of the corresponding true mixed venous tension group. The evidence, such as it is, is against this, but our data were too inexact and disperse to admit of a proper answer to this question. It is quite possible that the blood in the pulmonary capillaries after rebreathing the $\mathrm{CO}_{2}-\mathrm{O}_{2}$ mixtures, was not more than 97 or 98 per cent saturated with oxygen, instead of 100 per cent, in which case this would tend to offset the error due to oxygen absorption.

It may, however, fairly be concluded from this group of experiments that:

1. Equilibrium of lung-bag tensions with the tensions of the incoming venous blood can be achieved with respect to $\mathrm{CO}_{2}$ and $\mathrm{O}_{2}$ simultaneously, only if the mixed lung gases are, at the time when rebreathing is begun, within a very few millimeters of the actual mixed venous tensions. In other words, little adjustment can be made by the absorption or liberation of gases by the blood.

2. When true mixed venous equilibrium has been attained, these values, in respect to blood $\mathrm{CO}_{2}$ contents are at the same general level, and in each particular instance close to the corresponding value arrived at by a properly conducted oxygenated mixed venous tension determination. By "properly conducted," in the case of this subject it is meant that the initial tension of $\mathrm{CO}_{2}$ in the rebreathing bag shall be between 56 and $70 \mathrm{~mm}$.

The correspondence between the mixed venous $\mathrm{CO}_{2}$ contents as arrived at by these different methods, coupled with the definiteness with which an apparent equilibrium can be reached by both methods, 
strengthens materially, we believe, the inference that the $\mathrm{CO}_{2}$ tensions so obtained are actually the $\mathrm{CO}_{2}$ tensions of the mixed venous or pulmonary artery blood, at the moment when rebreathing is completed. The experiments confirm the conclusions reached in 1922 by Douglas and Haldane (13), but have extended their observations somewhat, in showing the process of equilibration more fully, and in giving more definite justification for the assumption of lung-blood equilibrium for respiratory gases.

It is of interest to calculate the volume output of the heart of this subject on the basis of our data. From analyses of expired air, on February 18, March 7, 11, 15, and May 3, the corrected figures for $\mathrm{CO}_{2}$ output were 217.5 cc., 198.3 cc., 223.8 cc., 222.7 cc., and 204.5 cc., an average of $213.4 \mathrm{cc}$. From table 7 , the average alveolar $\mathrm{CO}_{2}$ tension is found to be $43.9 \mathrm{~mm}$., and the average oxygenated mixed venous $\mathrm{CO}_{2}$ tension of groups II, III, and IV of this table, at the end of fifteen seconds' rebreathing, is $53.3 \mathrm{~mm}$. On the $\mathrm{CO}_{2}$ dissociation curve of this subject, $43.9 \mathrm{~mm}$. corresponds to 51.3 volumes per cent, and 53.3 $\mathrm{mm}$. to 55.5 volumes per cent. The volume output of the heart is thus $\frac{213.4}{(55.5-51.3) \times 10}=5.1$ liters per minute. As this subject has a surface area of 2.00 square meters, the cardiac output per square meter is 2.6 liters. This is higher than 2.2 liters, the normal standard which Grollman (28) has worked out by the use of his acetylene method of measuring circulation rate; considering the fact that conditions in our experiments were not rigidly basal, the agreement is fairly close.

The individual figures for circulation rate, as derived from the "true" mixed venous blood experiments, show considerable variation, due chiefly to variations in alveolar air values. The mixed venous $\mathrm{CO}_{2}$ content values for the five experiments in which an apparent equilibrium was reached were $55.9,55.9,55.7,55.0$, and 54.9 volumes per cent, an average of 55.5 volumes per cent,- - the same as for the oxygenated experiments. The corresponding alveolar air samples (41.6, 44.4. $46.3,44.5$, and $44.7 \mathrm{~mm}$.) gave an average arterial $\mathrm{CO}_{2}$ content of 51.5 volumes per cent. The circulation rate is then $\frac{213.4}{(55.5-51.5) \times 10}=$ 5.3 liters per minute. 
In the case of subject M. L. S., two experiments were performed, each consisting of one true and one oxygenated equilibration. In order that the results might be compared, a nomogram was constructed, as described above. In this instance, however, the number of points actually determined was small: two points on the oxygenated $\mathrm{CO}_{2}$ curve, one on the reduced curve, one point at $40 \mathrm{~mm} . \mathrm{CO}_{2}$ and $30 \mathrm{~mm}$.

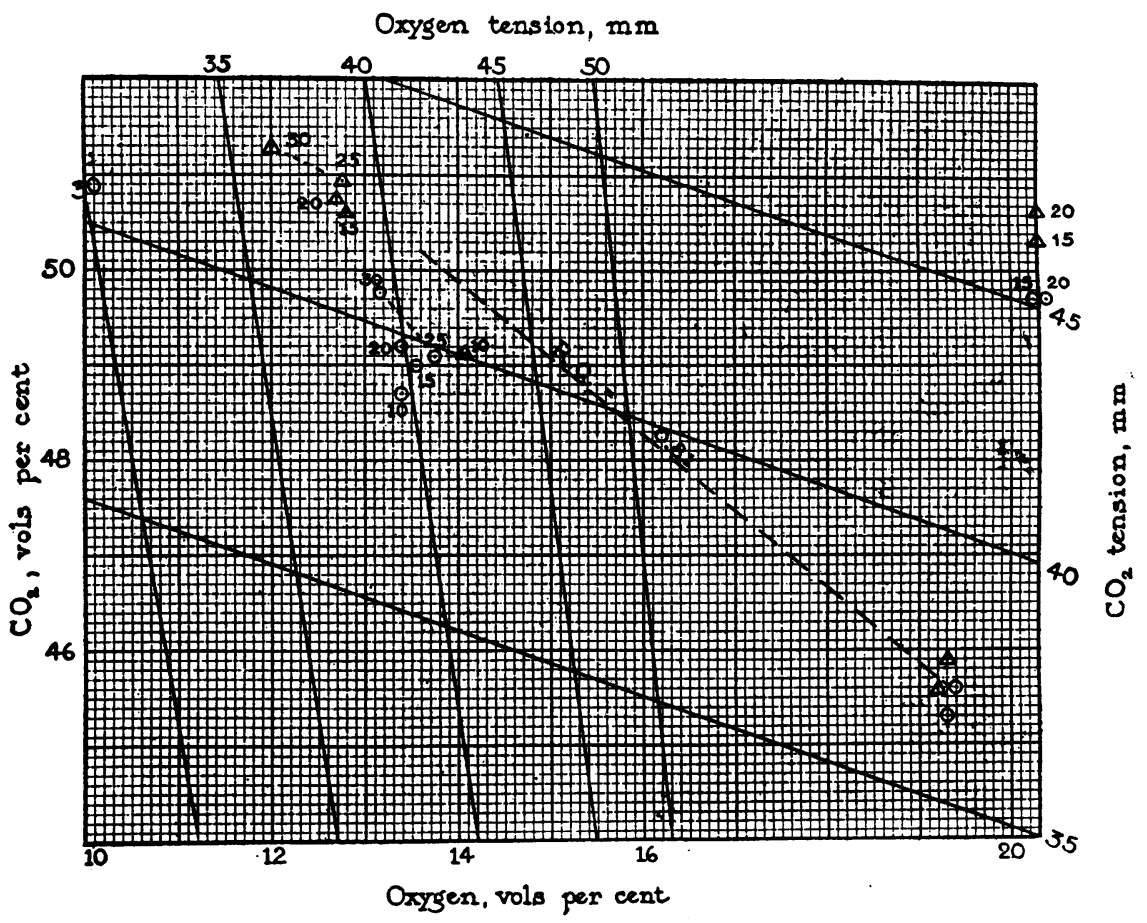

Fig. 9. $\mathrm{CO}_{2}-\mathrm{O}_{2}$ Nomogram of Blood of Subject M. L. S.

For explanation see figure 6, and text. Circles = experiments of February 25. Triangles = experiments of March 1.

$\mathrm{O}_{2}$ tensions, and one at $40 \mathrm{~mm} . \mathrm{CO}_{2}$ and $45 \mathrm{~mm} . \mathrm{O}_{2}$ tensions. These were sufficient to give the skeleton of a complete nomogram. The $\mathrm{CO}_{2}$ tension lines were drawn by using slopes and distances similar to those of the nomogram of D. W. R.; the error involved by this procedure, over the small area under consideration, is probably not great.

The nomogram is given in figure 9 , with the two pairs of experiments 
plotted on it. Expired air samples were not obtained, but average R.Q. lines $(=0.8)$ have been drawn from each of the alveolar air points. It will be seen that the points in each true venous tension experiment are fairly close together. The agreement in $\mathrm{CO}_{2}$ content level between the true and corresponding oxygenated points at equilibrium is fair: the average of fifteenth and twentieth second points show a difference of -0.6 volumes per cent ("true" less than oxygenated) in the first experiment, and +0.25 volumes per cent in the second. From the position of the R.Q. lines, the latter would appear to be closer to the true mixed venous point.

As in the experiments with subject D. W. R., it can be said that "true" and oxygenated methods appear to give the same general level of venous $\mathrm{CO}_{2}$ content. The average oxygen utilization or arteriovenous difference, for this subject was 5.6 volumes per cent.

The recent experiments of Lauter with Bauman and Friedländer (25), in which blood was taken directly from the right hearts of human subjects in the resting basal state, showed the average blood flow to be about 4.5 liters per minute, and the average arteriovenous oxygen difference 5 volumes per cent. This compares well with the above results on the two subjects of our experiments, under non-basal conditions. As we studied only two subjects, no conclusion can be drawn as to the absolute accuracy of the results we have obtained, but this comparison of indirect with direct mixed venous blood determinations suggests that the unproved assumptions (see Part I) which we have made in these experiments-particularly relative to respiratory movement and recirculation of blood-do not involve any large error.

\section{SUMMARY}

From the data presented in this paper, the following summary of results obtained may be given:

1. For the investigation of mixed venous blood gases in man at rest, two normal subjects were studied. The methods employed were simple, involving the rebreathing of gas mixtures from a bag, and the taking of instantaneous samples at intervals of 5 seconds during the rebreathing period. The latter lasted usually about 30 seconds, sometimes as long as $\mathbf{5 0}$ seconds. 
2. In the experiments in which oxygenated mixed venous blood was studied, it was found that a "plateau" level for $\mathrm{CO}_{2}$ tensions could be obtained regularly near the fifteenth second after beginning rebreathing, providing suitable initial $\mathrm{CO}_{2}$ tensions were used in the rebreathing bag. These tensions could be varied within well defined limits, the lower limit being a value about $2 \mathrm{~mm}$. higher than the resulting equilibrium level; and the upper limit about $15 \mathrm{~mm}$. above this level in the case of one subject, and $10 \mathrm{~mm}$. above in the case of the other. The equilibrium level was on the average practically the same for all bag mixtures used, within these limits.

3. Below this lower limit of initial $\mathrm{CO}_{2}$ tension, no constant plateau level was reached during rebreathing. Above the upper limit of initial $\mathrm{CO}_{2}$ tension, plateaux were found which were definitely above those reached by the lower tensions.

4. The plateaux, or equilibrium levels of $\mathrm{CO}_{2}$ tension, were not quite horizontal, but showed slight upward inclination. It was thought that this might be due in part to progressive oxygen absorption during the interval, and in part to recirculation of small volumes of blood.

5. The definiteness of the plateau or equilibrium levels was indicated by the facts $(a)$ that they occurred regularly over the same time interval, (15 to 20 seconds), (b) that the deviations in slope of individual experiments from the average were much less over this interval than over earlier and later intervals, and $(c)$ that widely different initial concentrations of $\mathrm{CO}_{2}$ in the rebreathing bag were brought to the same equilibrium level at the end of rebreathing.

6. The actual equilibrium levels of mixed venous $\mathrm{CO}_{2}$ varied with the time of day, and varied from one day to another. Successive experiments on the same morning with the subject remaining at rest, gave levels varying by less than $1 \mathrm{~mm}$. of $\mathrm{CO}_{2}$.

7. In the experiments in which it was attempted to establish true mixed venous equilibrium (in respect to both $\mathrm{CO}_{2}$ and $\mathrm{O}_{2}$ tensions) between lungs and blood, it was found that the mixed lung and bag gases had to be close to the actual venous tensions, in order for equilibrium to be established in the lung gases before recirculation of blood began.

8. One experiment in which arterial blood was drawn while such a rebreathing experiment was being done, showed that, near the mixed 
venous level, at the time when the lung gases were in apparent equilibrium, lung tensions and blood tensions were nearly the same.

9. By plotting on a blood nomogram oxygenated and true mixed venous tension experiments, it was found that successive experiments done by the two methods gave approximately the same venous $\mathrm{CO}_{2}$ contents at the equilibrium levels.

10. The time when appreciable amounts of blood began to recirculate, in the cases of the two subjects of these experiments, was usually between 20 and 25 seconds. This was indicated by $(a)$ the time when oxygenated $\mathrm{CO}_{2}$ tensions began to show a sharp upward trend, after the plateau level; $(b)$ the time when oxygen tensions, in the true mixed venous tension experiments, after an initial steady increase, began to decrease again.

11. Experiments in which successive rebreathing periods were employed, leaving the bag mixture unchanged between periods, gave equilibrium levels definitely lower than either of the other two groups of experiments, in the case of one of the two subjects. It was concluded that for this subject, the successive rebreathing method did not give mixed venous values. It was suggested also that this might account for some of the high values for circulation rate obtained with circulation rate methods in which this technique was used.

12. Calculations of circulation rate, in one of the two subjects, gave the following average values: $(a)$ from the oxygenated mixed venous $\mathrm{CO}_{2}$ tension values, 5.1 liters per minute; $(b)$ from the true mixed venous $\mathrm{CO}_{2}$ values, 5.3 liters per minute. Circulation rate per square meter of body surface (conditions not basal), 2.6 liters per minute.

13. The arteriovenous oxygen difference for one subject was 5.1 volumes per cent, for the other 5.6 volumes per cent. This compares closely with the values obtained by Lauter, by direct cardiac puncture in man.

\section{CONCLUSION}

1. By the use of a simple technique of rebreathing $\mathrm{CO}_{2}-\mathrm{O}_{2}-\mathrm{N}_{2}$ mixtures, with samples taken every 5 seconds during the procedure, the course of equilibration of lung air with incoming venous blood has been studied. It has been found that an equilibrium can be regularly 
established, for $\mathrm{CO}_{2}$ with certain high oxygen mixtures, and for both $\mathrm{CO}_{2}$ and $\mathrm{O}_{2}$ with certain low oxygen mixtures. These two equilibria represent essentially the same $\mathrm{CO}_{2}$ content levels in the (venous) blood of the subject. The mixtures of rebreathed gases that can be used to establish such equilibria can be varied within small but fairly well defined limits.

2. To accept these equilibria as representing the state of the mixed venous blood at rest involves certain assumptions; these have been described in the first part of the present study. Previous workers have shown that (a) with proper technique complete mixture of lungbag gases is attainable; $(b)$ "true" and "oxygenated" mixed venous $\mathrm{CO}_{2}$ levels are the same. Our experiments have confirmed the above and have further shown that $(c)$ the error due to progressive oxygen absorption during the oxygenated mixed venous equilibration is small, (d) lung gases and blood are in approximate equilibrium at the end of a "true" mixed venous equilibration, $(e)$ the method of intermittent rebreathings gives false "mixed venous" equilibria in one of the subjects studied.

3. No further evidence has been obtained as to the presence or extent of error due to $(a)$ altered respiratory movements during the procedure, or $(b)$ recirculation within the time of the procedure, of small amounts of blood; but the comparison of our arteriovenous differences with those recently obtained by Lauter with direct cardiac puncture, suggests that the error involved here is small.

\section{BIBLIOGRAPHY}

1. Fick, A., Sitzungsb. d. phys.-med. Gesellsch. zu Würzburg, 1870, 16. Ueber die Messung des Blutquantums in den Herzventrikeln.

2. Loewy, A. and von Schrötter, H., Ztschr. f. exp. Path. u. Therap., 1905, i, 197. Untersuchungen über die Blutcirculation beim Menschen.

3. Plesch, J., Ztschr. f. exper. Path. u. Therap., 1909, vi, 380. Hämodynamische Studien.

4. Christiansen, J., Douglas, C. G., and Haldane, J. S., J. Physiol., 1914, xlviii, 244. The Absorption and Dissociation of Carbon Dioxide by Human Blood.

5. Fridericia, L. S., Biochem. Ztschr., 1918, lxxxv, 307. Untersuchungen an Menschen über Sauerstoff und Kohlensäurespannung im Blut der Pulmonalarterie, und über Messung des Minutenvolumens des Herzens.

6. Liljestrand, G., and Lindhard, J., J. Physiol., 1920, liii, 420. The Determination of the Circulation Rate in Man from the Arterial and Venous $\mathrm{CO}_{2}$ Tension and the $\mathrm{CO}_{2}$ Output. 
7. Krogh, A., and Lindhard, J., Skandin. Arch. f. Physiol., 1912, xxvii, 100. Measurements of the Blood Flow through the Lungs of Man.

8. Henderson, Y., and Prince, A. L., J. Biol. Chem., 1917, xxxii, 325. Applications of Gas Analysis. II. The $\mathrm{CO}_{2}$ Tension of the Venous Blood and the Circulation Rate.

9. Meakins, J. C., and Davies, H. W., Heart, 1922, ix, 191. The Influence of Circulatory Disturbances on the Gaseous Exchange in the Blood. II. A Method of Estimating the Circulation Rate in Man.

10. Barcroft, J., Roughton, F. J. W., and Shoji, R., J. Physiol., 1921, lv, 371. The Measurement of the Oxygen Content of the Mixed Venous Blood and of the Volume of Blood Circulating per Minute.

11. Redfield, A. C., Bock, A. V., and Meakins, J. C., J. Physiol., 1922, lvii, 76. The Measurement of the Tension of Oxygen and Carbon Dioxide in the Blood of the Pulmonary Artery in Man.

12. Grollman, A., Am. J. Physiol., 1930, xciii, 116. A Comparison of the Triple Extrapolation (Fick Principle) and the Acetylene (Foreign Gas Principle) Methods for the Determination of Cardiac Output of Man.

13. Douglas, C. G., and Haldane, J. S., J. Physiol., 1922, lvi, 69. The Regulation of the General Circulation Rate in Man.

14. Ewig, W., and Hinsberg, K., Klin. Wchnschr., 1930, ix, 647. Über die Bestimmung des Minutenvolumens.

15. Murray, C. D., and Taylor, H., J. Physiol., 1925, lix, lxvii. Method for the Determination of the Oxygen and Carbon Dioxide Tensions in Mixed Venous Blood.

16. Field, H., Jr., Bock, A. V., Gildea, E. F., and Lathrop, F. L., J. Clin. Invest., 1924, $i, 65$. The Rate of the Circulation of the Blood in Normal Resting Individuals.

17. Bock, A. V., Dill, D. B., and Talbott, J. H., J. Physiol., 1928, lxvi, 121. Studies in Muscular Activity. I. Determination of the Rate of Circulation of Blood in Man at Work.

18. Richards, D. W., Jr., and Strauss, M. L., J. Clin. Invest., 1928, v, 161. Circulatory Adjustment in Anemia.

19. Isräels, M. C. G. and Lamb, F. W., J. Physiol., 1929, lxvii, 49, and 315. The Determination of the Carbon Dioxide Content of the Mixed Venous Blood. I and II.

20. Burwell, C. S., and Robinson, G. C., J. Clin. Invest., 1924, i, 47. A Method for the Determination of the Amount of Oxygen and Carbon Dioxide in the Mixed Venous Blood of Man.

21. Grollman, A., and Marshall, E. K., Jr., Am. J. Physiol., 1928, lxxxvi, 110. The Time Necessary for Rebreathing in a Lung-Bag System to Attain Homogeneous Mixture.

22. Sonne, C., Deutsch. Arch. f. klin. Med., 1918, cxxiv, 358. Utber die Bestimmung des Unterschiedes zwischen arterieller und venöser Kohlensäurespannung. u.s. w. 
23. Hamilton, W. F., Moore, J. W., and Kinsman, J. M., Am. J. Physiol., 1927, Ixxxii, 656. Delay of Blood in Passing through the Lungs as an Obstacle to the Determination of the $\mathrm{CO}_{2}$ Tension of the Mixed Venous Blood.

24. Forssmann, W., Klin. Wchnschr., 1929, viii, 2085. Die Sondierung des Rechten Herzens.

25. Lauter, S., Kreislaufprobleme. Münch Med. Wchnschr., 1930, Ixxvii, 526.

26. Marshall, E. K., Jr., Medicine, 1930, ix, 175. The Cardiac Output of Man.

27. Bock, A. V., Dill, D. B., Edwards, H. T., Henderson, L. J., and Talbott, J. H., J. Physiol., 1929, lxviii, 277. On the Partial Pressures of Oxygen and Carbon Dioxide in Arterial Blood and Alveolar Air.

28. Grollman, A., Am. J. Physiol., 1929, xc, 210. Physiological Variations in the Cardiac Output of Man. VI. The Value of the Cardiac Output of the Normal Individual in the Basal, Resting Condition.

29. Higgins, H. L., Am. J. Physiol., 1914, xxxiv, 114. The Influence of Food, Posture, and Other Factors on the Alveolar Carbon Dioxide Tension in Man.

30. Dodds, E. C., J. Physiol., 1921, liv, 342. Variations in Alveolar Carbon Dioxide Pressure in Relation to Meals.

31. Cullen, G. E., and Earle, I. P., J. Biol. Chem., 1929, lxxxiii, 545. Studies on the Acid-Base Condition of Blood. II. Physiological Changes in Acid-Base Condition Throughout the Day.

32. Porges, O., Leimdörfer, A., and Markovici, E., Ztschr. f. Klin. Med., 1911, lxxiii, 389. Ueber die Kohlensäurespannung des Blutes in Pathologischen Zuständen.

33. Richards, D. W., Jr., and Strauss, M. L., J. Clin. Invest., 1927, iv, 105. Oxy-hemoglobin Dissociation Curves of Whole Blood in Anemia.

34. Austin, J. H., Cullen, G. E., Hastings, A. B., McLean, F. L., Peters, J. P., and Van Slyke, D. D., J. Biol. Chem., 1922, liv, 121. Studies of Gas and Electrolyte Equilibria in Blood. I. Technique for Collection and Analysis of Blood and for Its Saturation with Gas Mixtures of Known Composition.

35. Van Slyke, D. D., and Neill, J. M., J. Biol. Chem., 1924, lxi, 523. The Determination of Gases in Blood and Other Solutions by Vacuum Extraction and Manometric Measurement. I.

36. Peters, J. P., Eisenman, A. J., and Bulger, H. A., J. Biol. Chem., 1923, lv, 709. Studies of the Carbon Dioxide Absorption Curve of Human Blood. II. The Nature of the Curve Representing the Relation of $\mathrm{pH}$ to $\mathrm{BHCO}_{3}$.

37. Bock, A. V., Dill, D. B., Hurxthal, L. M., Lawrence, J. S., Coolidge, T. C., Dailey, M. E., and Henderson, L. J., J. Biol. Chem., 1927, lxxiii, 749. Blood as a Physico-Chemical System. V. The Composition and Expiratory Exchanges of Normal Human Blood During Work.

38. Eppinger, H., v. Papp, L., and Schwarz, H., Utber das Asthma Cardiale. Berlin, 1924. 